\title{
Un panorama de la teoría arqueológica en el Perú de comienzos del siglo XXI
}

Recibido: $24 / 03 / 2020$

Aprobado: 10/06/2020

Publicado Online: 20/07/2020
HENRY TANTALEÁN

Universidad Nacional Mayor de San Marcos

htantaleany@unmsm.edu.pe

\section{RESUMEN}

En este artículo presentamos un panorama de la teoría arqueológica desarrollada en el Perú de las últimas dos décadas. Con ese objetivo, en primer lugar, se plantea el lugar y naturaleza de la teoría en la práctica arqueológica peruana. En segundo lugar, se describen sintéticamente los contextos políticos y económicos en los cuales se ha desarrollado la práctica arqueológica de los últimos años. En tercer lugar, se describe un panorama de las teorías arqueológicas utilizadas en nuestro país, enfocándonos en los principales temas de estudio desarrollados. En cuarto lugar, se revisan otros tópicos teóricos relevantes que se han desarrollado en la arqueología peruana. Finalmente, se dejan planteados algunos temas que merecerían mayor desarrollo teórico en la arqueología peruana.

Palabras clave: Teoría, arqueología peruana, evolucionismo, historicismo-cultural, procesualismo, posprocesualismo.

\section{An overview of the archaeological theory in Peru in the early Twenty-first Century}

\begin{abstract}
In this article, we present an overview of the archaeological theory developed in Peru in the last two decades. For that purpose, first, the place and nature of the theory in Peruvian archaeological practice is considered. Secondly, the political and economic contexts in which the archaeological practice of recent years has developed are briefly described. Third, an outlook of the archaeological theories used in our country is described, focusing on the main developed topics of study. Fourth, other relevant theoretical topics that have been developed in Peruvian archaeology are reviewed. Finally, some issues that deserve further theoretical development in Peruvian archaeology are introduced.
\end{abstract}

Keywords: Theory, Peruvian archaeology, Evolutionism, Cultural Historicism, Processualism, Post-Processualism. 
I a teoría arqueológica surge de nuestra aproximación reflexiva y sistemática a la realidad de nuestro objeto de estudio: los restos arqueológicos. En ese proceso intelectual y práctico, la teoría arqueológica previamente generada por los investigadores, y la que hemos incorporado en nuestra experiencia, nos proporciona una serie de modelos, conceptos y categorías (cuestiones de orden ontológico) que nos posibilitan generar formas de comprensión de las sociedades pasadas para producir conocimiento (cuestiones de orden epistemológico).

De hecho, consciente o inconscientemente todos los arqueólogos y arqueólogas utilizan elementos de teorías arqueológicas al entrar en un diálogo inevitable con los restos materiales bajo su estudio. De la dialéctica generada en este encuentro se producen las explicaciones arqueológicas. Dichas síntesis son las que nos ofrecen una certidumbre temporal sobre los fenómenos sociales que estamos investigando y, a la vez, nos permite reconocer causalidades y regularidades.

Como era de esperar, debido a la gran cantidad de vestigios arqueológicos, su complejidad y monumentalidad temprana, el territorio peruano no ha estado exento del desarrollo y aplicación de teorías arqueológicas. Casi desde el mismo inicio de la disciplina científica, a finales del siglo XIX, las más innovadoras teorías de su momento formaron parte de las explicaciones y narrativas del pasado prehispánico.

También, como en gran parte del mundo, a lo largo del siglo XX muchas otras teorías arqueológicas, especialmente las hegemónicas, han llegado de la mano de investigadores extranjeros, pero también han sido incorporadas por investigadores nacionales formados o influenciados por ese pensamiento científico. Como describiremos y detallaremos más adelante, las principales aproximaciones, tendencias, escuelas o posiciones teóricas arqueológicas como el evolucionismo, historicismo cultural, marxismo, procesualismo y posprocesualismo han surgido y sido desarrolladas por los investigadores para dar cuenta de los fenómenos arqueológicos. Aparentemente todas esas teorías arqueológicas, en la manera en que Bruce Trigger (2006) las había planteado en su famoso Historia del pensamiento arqueológico, también han estado presentes en la arqueología peruana.

Obviamente, la intensidad con la que dichas teorías arqueológicas han impactado en la práctica arqueológica en el Perú ha sido diferente a la de otras partes del mundo. Especialmente porque dentro del concierto de los países que generan y aplican las nuevas teorías arqueológicas, principalmente el 
mundo anglosajón, Perú resulta ser un país periférico dentro de la academia arqueológica internacional (Dillehay, 2008, p. 168). Asimismo, los contextos históricos, especialmente políticos y económicos, han condicionado o apoyado el desarrollo de ciertas teorías arqueológicas. Afortunadamente existe una importante descripción y reflexión sobre el desarrollo de las teorías arqueológicas en el Perú en una perspectiva general y de largo aliento que nos permite entender cómo se han realizado dichas aplicaciones teóricas (Asensio, 2018; Tantaleán, 2016; López-Hurtado 2014; Tantaleán y Astuhuamán, 2013; Shimada y Vega-Centeno, 2011; Herrera, 2008; Dillehay, 2008; Burger, 1989; Schaedel y Shimada 1982). Por tanto, resulta innecesario abundar en esta cuestión.

Sin embargo, a comienzos del siglo XXI, principalmente por ser un periodo muy reciente, pero sobre todo por tener una importante cantidad de arqueólogos y arqueólogas trabajando en el Perú, se hace todo un reto establecer cuáles son las principales tendencias teóricas en la práctica de la arqueología peruana contemporánea. No obstante, existen algunos elementos comunes en las investigaciones que podemos utilizar para proponer un panorama de dichas teorías, especialmente tomando como base los principales temas abordados en la arqueología peruana.

Así, en este artículo se realiza un esbozo de la teoría arqueológica desarrollada y/o aplicada en la arqueología peruana en las últimas dos décadas. Para ello, se utilizan los recientes trabajos publicados por arqueólogos y arqueólogas peruanos y extranjeros en las principales áreas geográficas donde estos se ha desarrollado con mayor intensidad y visibilidad. Como veremos, el desarrollo y aplicación de teorías arqueológicas se presenta desigual para el territorio peruano.

\section{Las teorías arqueológicas}

En la actualidad, el estudio y el análisis del desarrollo y aplicación de las teorías arqueológicas son un campo de estudio por derecho propio en la literatura científica a nivel mundial (Urban y Shortmann, 2019; Harris y Cipolla, 2017; Preucel y Mrozowski, 2010; Bentley et al., 2009; Moro Abadía, 2007; Trigger, 2006, 1989; Jones 2001; Johnson, 1999; Preucel y Hodder, 1996; Dark 1995; Ucko, 1995; Yoffee y Sherrat, 1993; Hodder 1992, 1991, 1986; Shanks y Tilley 1987a, 1987b; entre otros). Asimismo, desde unas décadas 
atrás existen diversas reuniones científicas en las cuales se discute la teoría arqueológica y su práctica. Así, a nivel mundial, desde 1977, el Theoretical Archaeology Group (TAG) ha reunido a investigadores para discutir la teoría arqueológica en el mundo anglosajón (Jones y Johnson, 1990). Una iniciativa que se ha propagado por diferentes partes del mundo (Crossland y Flemming, 2014). En Latinoamérica, desde 1998 hasta la actualidad, la Reunión de Teoría Arqueológica en América del Sur (TAAS) ha contribuido a la discusión de la teoría en y desde los países latinoamericanos.

De este modo, la teoría arqueológica es un importante campo de estudio y merece un lugar dentro de las discusiones sobre la práctica de la arqueología, sobre todo en el Perú, un lugar lleno de restos arqueológicos que han sido, son y serán explicados a la luz de las teorías arqueológicas. Sin embargo, ¿qué entendemos como teorías arqueológicas?

Las teorías arqueológicas, como otras teorías desarrolladas o aplicadas en otras disciplinas del conocimiento humano, se originaron de la observación directa de la realidad de estudio específica. En el caso de nuestra disciplina, las teorías arqueológicas se originaron de la observación de la realidad arqueológica, concretamente de los restos materiales producto de la actividad humana de la cual, muchas veces, no tenemos información escrita. Por tanto, el objetivo del desarrollo o aplicación de teorías arqueológicas es la reconstrucción de las prácticas sociales que dejaron como resultado a los restos arqueológicos. Como señala Trigger (2006, p. 28; la traducción es nuestra): “En la actualidad, existe una tendencia creciente a ver a la teoría arqueológica como un subconjunto de la teoría antropológica (o ciencia social) que aborda cómo el comportamiento y las creencias humanas están relacionadas con la cultura material y como la cultura material influye en el comportamiento humano".

También para los autores de un libro recientemente publicado, la teoría arqueológica se trata del: "[...] cómo organizamos nuestras interpretaciones, cómo reconocemos y definimos el dato [arqueológico]; las diferentes preconcepciones, ideas y creencias que nosotros llevamos al diálogo con otra persona" (Harris y Cipolla, 2017, p. 2; la traducción es nuestra).

Asimismo, Matthew Johnson (1999, p. 217; la traducción es nuestra) problematizaba la definición de la teoría arqueológica de la siguiente manera:

Mi definición preferida [de teoría arqueológica] es "el orden en el que colocamos los hechos", en parte porque es una definición breve y accesible, en parte porque me parece laxa en lugares precisos y permite la coexistencia de diferentes perspectivas teóricas dentro de tal definición (aunque no todas, lo debo admitir). Más 
importante y fundamental, esta definición pone atención en la forma en que los datos y la teoría están relacionados dialécticamente. En otras palabras, "datos" y "teoría" tienen que ser comprendidos como parte de una totalidad mayor en la cual la naturaleza de una no puede ser comprendida sin la otra.

Sin embargo, también como señalaba Johnson (1999, p. 217; la traducción es nuestra): "La manera en que uno define la teoría, por tanto, depende del punto de vista teórico de uno mismo". De esta manera, no existirá una sola manera de definir a la teoría arqueológica, pues la misma teoría arqueológica también está influenciada y conceptualizada por la propia posición teórica de su practicante. Aún con todo, resulta evidente de la lectura de las definiciones alcanzadas previamente y de otras definiciones de teoría arqueológica que existe una serie de coincidencias y elementos comunes en las variadas maneras de definirla.

Así pues, se hace obligado, al escribir desde una experiencia vital, formación y posición teórica arqueológica concreta, una definición de la teoría arqueológica. Por tanto, aquí definimos a la teoría arqueológica como el conjunto de generalizaciones, modelos, conceptos y categorías que surgen del diálogo constante entre los investigadores-arqueólogos y la evidencia arqueológica. ${ }^{1}$

En el caso de la arqueología, a lo largo de su historia y dependiendo de sus contextos históricos de desarrollo, muchas otras teorías (y, por supuesto, metodologías imbricadas) desarrolladas en otros campos de estudio fueron integradas para dar cuenta de los fenómenos arqueológicos. De esta manera, la biología, física, antropología, sociología, historia, etc., fueron disciplinas científicas que contribuyeron en diferentes intensidades para formar lo que conocemos como teorías arqueológicas. Incluso la experiencia personal de cada investigador contribuyó a generar las teorías arqueológicas. Así, las teorías arqueológicas existen en tanto la práctica de los arqueólogos y arqueólogas que las han ido utilizando, contrastando, desechando o mejorando con respecto a la realidad arqueológica estudiada. Por tanto, en términos operativos y prácticos, las teorías arqueológicas son medios para aproximarnos inicialmente de una manera reflexiva, sistemática y dinámica a la comprensión de nuestro objeto de conocimiento: las sociedades humanas pasadas.

1 Como señalan Lull y Micó (1997, p. 107): “[La teoría arqueológica] es un sistema de conceptos que rige los planos ontológico, epistemológico y político-didáctico de la práctica arqueológica". 
Como hemos señalado, diferentes autores (Renfrew y Bahn, 2000; Willey y Sabloff, 1980) han tratado de establecer cuáles fueron las principales teorías desarrolladas en la arqueología. Pese a la diversidad, siguiendo a diferentes autores (Urban y Schortman, 2019; Johnson, 1999; Trigger, 2006, 1989; Lull y Micó, 2002-2001, 1998, 1997), podríamos establecer que a lo largo de su historia los arqueólogos y arqueólogas se pueden relacionar con cinco grandes tendencias teóricas: evolucionismo social, historicismo-cultural, marxismo, procesualismo y posprocesualismo.

El evolucionismo social fue la primera teórica científica que surgió en la arqueología a finales del siglo XIX (Trigger, 2006). Se basó en la teoría de la evolución biológica planteada por Charles Darwin que para la antropología se tradujo como evolucionismo social, desarrollado principalmente por Lewis Morgan. Si bien previamente existía una ideología del progreso humano y que investigadores como Herbert Spencer y otros plantearon visiones evolucionistas sociales (Harris, 1979, p. 93), la publicación de Ancient Society en 1877 por Morgan estableció un corpus de datos etnográficos que soportaban su conocida escala de evolución humana de salvajismo, barbarie y civilización. Investigadores que trabajaron en el Perú como George Dorsey o Max Uhle estuvieron influenciados por esta teoría. Su influencia teórica en la arqueología se percibe, sobre todo, en la manera gradual y progresista en la que se comprende el cambio social.

Por su parte, el historicismo-cultural es una teoría arqueológica que resalta las particularidades de cada "cultura" (Trigger, 2006, p. 232). Su lógica histórica supone que los cambios sociales se dan por factores externos al "organismo social", en este caso la cultura. Aunque el concepto de cultura se desarrolló en Europa Central a finales del siglo XIX, esta teoría fue desarrollada, principalmente, en Europa Occidental y los Estados Unidos en la primera mitad del siglo XX. Su principal representante en este último país fue el antropólogo Franz Boas (Trigger 2006:279). Esta propuesta encontró entre sus máximos exponentes en el Perú a Alfred Kroeber y a Julio C. Tello. Sin embargo, pese a su antigüedad, muchos de los elementos ontológicos y epistemológicos sobreviven hasta la actualidad (Dillehay, 2008, p. 168, 170).

Otras de las teorías relevantes para la arqueología es el marxismo (Urban y Schortman, 2019; Bentley y Maschner, 2009). En la práctica arqueológica, esta teoría se fundamenta principalmente en los textos que explican la historia de las sociedades generados por Karl Marx, Frederic Engels y sus seguidores. Esta teoría utiliza varias de las ideas y conceptos surgidos en el marxismo, en 
especial su perspectiva materialista y dialéctica del mundo y la sociedad. Uno de sus principales practicantes en Europa fue Gordon Childe (Trigger, 2006, p. 344). En los Estados Unidos también se desarrolló esta tendencia teórica y existen arqueólogos como Randall McGuire o Thomas Patterson quienes hicieron explícita su perspectiva teórica marxista en la arqueología. En el Perú, sus máximos exponentes en la arqueología fueron Emilio Choy (1979) y Luis G. Lumbreras (1974). Incluso, Lumbreras junto con otros colegas latinoamericanos fundaron la denominada Arqueología Social Latinoamericana, la cual tuvo cierta influencia en la arqueología peruana (Dillehay, 2008, p. 167). Sin embargo, la arqueología marxista en el Perú retuvo elementos evolucionistas, histórico-culturales y, a la vez, asimiló aportes del procesualismo.

Por otra parte, el procesualismo es una renovación teórica del evolucionismo social al cual se le dotó de una epistemología cientificista, se le añadieron visiones economicistas de la sociedad y se le incorporó importantes innovaciones metodológicas (Trigger, 2006; Johnson, 1999). Surgido del neoevolucionismo de la década de 1960 desarrollado por antropólogos norteamericanos como Leslie White y Julian Steward, el procesualismo tuvo entre sus principales líderes en la arqueología a Lewis Binford, Kent Flannery y David Clarke. En el Perú, el procesualismo se incorporó tempranamente a finales de la década de 1970 gracias a investigadores como Timothy Earle, Kent Flannery y Joyce Marcus, entre otros (Burger, 1989, p. 43). Para finales de la década de 1990, Michelle Hegmon (2003, p. 214) encontró dentro del procesualismo norteamericano tres perspectivas explícitas: i) ecología evolutiva, ii) arqueología conductual y iii) arqueología darwinista, también llamada arqueología evolutiva.

Sin embargo, a inicios de la década de 1980, el procesualismo ya había recibido críticas importantes por parte del posprocesualismo (Hodder, 1986) $\mathrm{y}$, en algunos casos, dichas críticas fueron tomadas en cuenta y se asumieron nuevos elementos antes no considerados que sofisticaron el procesualismo clásico (García, 2012, p. 98). Así, en la arqueología procesualista comenzaron a aparecer elementos de la teoría de la agencia (Giddens, 1979; Bourdieu, 1977), estudios de cultura material (Miller y Tilley, 1996; Miller, 1986), neomarxismo (Bourdieu 1977; Foucault, 1977; Althusser, 1971), poscolonialismo (Spivak, 1999; Bhabha, 1994; Said, 1978), género (Butler, 1993; Moore, 1988; Leacock 1981), y simbolismo y ritual (Rappaport, 1999; Turner, 1969) que enriquecieron esta tendencia. Incluso, para inicios del siglo XXI se llegó a establecer la existencia de un "procesualismo plus" (Hegmon, 2003) y, más 
recientemente, de un "neoprocesualismo" (García, 2012). En el Perú, dado el impacto que la arqueología procesualista ha tenido en las investigaciones, hemos observado como en las últimas décadas también ha ido sofisticándose, diversificándose e incorporando perspectivas humanistas. Como en el caso de otras perspectivas teóricas, pese a plantearse como un cambio paradigmático, muchos elementos del historicismo cultural perviven en sus explicaciones sociales.

Como hemos señalado arriba, en la década de 1980 surgió el denominado posprocesualismo que tuvo entre sus principales influencias a la filosofía posmoderna, el postestructuralismo, la teoría crítica y el marxismo estructuralista. El posprocesualismo surgió como una perspectiva crítica principalmente a la arqueología procesualista y su cientificismo. Sus principales impulsores fueron los británicos Ian Hodder, Michael Shanks, Christopher Tilley y Julian Thomas. En realidad, a diferencia de las teorías arqueológicas previas, en el posprocesualismo coexisten una diversidad de enfoques teóricos. En el Perú, la arqueología posprocesual no tuvo un impacto importante y lo que más bien se puede percibir es que algunos investigadores tomaron elementos de esta aproximación arqueológica y los incorporaron en sus propias posiciones teóricas. Incluimos aquí a las nuevas propuestas teóricas influenciadas por la filosofía fenomenológica (Heidegger, 1973; Merleau-Ponty, 1962), la antropología simétrica (Latour, 1993), los nuevos materialismos (Gell, 1998; Miller, 1987) y el perspectivismo amerindio (Viveiros de Castro, 2010; Descola, 2005). Como veremos, en el Perú esta perspectiva teórica, aunque tardíamente, ha empezado a ser deslizada muy recientemente en algunas investigaciones arqueológicas.

Como hemos observado, no obstante tales demarcaciones teóricas, hacemos hincapié en que más que teorías, "tradiciones" o "escuelas" arqueológicas monolíticas usadas por los investigadores, más bien lo que existen son una serie de "posiciones teóricas", como ya ha planteado previamente Manuel Gándara (1993). ${ }^{2}$ Como se verá, en general los arqueólogos y arqueólogas que investigan en el Perú como los de otros países, desarrollan posiciones teóricas, a veces explícitamente - aunque, por lo general, implícitamente- y que se pueden alejar o acercar de las teorías arqueológicas principales (por

2 Según el autor mexicano, una posición teórica es: "a. Un conjunto de supuestos valorativos, ontológicos y epistemológico-metodológicos. b. Que guían el trabajo de una comunidad académica particular. c. Y que permiten la generación y el desarrollo de teorías sustantivas. d. Algunas de estas teorías sustantivas cumplen un papel especial en la socialización de nuevos miembros de la comunidad, al ser consideradas como ejemplos a seguir al aplicar la posición teórica" (Gándara, 1993, p. 7). 
ejemplo: el evolucionismo, el historicismo cultural, el marxismo o el procesualismo mencionados). En este punto, vale la pena señalar que lo que hace este artículo es tratar de rastrear que teorías arqueológicas generales o posiciones teóricas fueron las que inspiraron y marcaron más profundamente a los investigadores en ciertos momentos. Como señala nuevamente Gándara (1993, p. 11): “[...] no hay, normalmente, ejemplos 'puros' de una posición [teórica]. Esto significa que, salvo quizá por los originadores y campeones de una position teórica, la mayoría de sus seguidores suelen incorporar, con un eclecticismo a veces no detectado o asumido, elementos de otras posiciones".

En general, lo que podemos reconocer en un rápido análisis de las posiciones teóricas al uso en los Andes centrales es que existe una predominancia en aplicar elementos de una o varias teorías a la hora de hacer un trabajo de investigación. Por tanto, en este panorama identificamos los componentes teóricos más evidentes utilizados o hechos explícitos por los investigadores en una publicación concreta con respecto a un tema de investigación específico. Así, lo que se observa es que, a pesar que en términos cronológicos algunas de dichas teorías deberían haber sido superadas, refutadas o cambiadas por otras más novedosas (un cambio de paradigma, sensu Kuhn), muchos autores aun incluyen dentro de sus explicaciones arqueológicas algunos elementos de teorías precedentes.

Sin embargo, antes de ver los temas desarrollados en la arqueología peruana que nos interesan y sus implicaciones teóricas, vale la pena contextualizar históricamente como se ha dado el desarrollo de la arqueología peruana en los últimos veinte años. Creemos necesario esto porque comprendemos que los arqueólogos y las arqueólogas habitamos en un mundo en el que las situaciones históricas y las ideologías contemporáneas condicionan nuestro trabajo arqueológico.

\section{EI desarrollo de la arqueología peruana en las últimas dos décadas}

El cambio de siglo trajo al Perú una nueva época de mayor democracia y florecimiento económico. La caída del gobierno de Alberto Fujimori en noviembre de 2000 y la asunción de Valentín Paniagua como presidente transitorio marcó un nuevo tiempo en el cual se democratizaron las formas de pensamiento, especialmente político, y se consolidó una mejor situación macroeconómica sobre la base de las políticas económicas neoliberales establecidas e impulsadas 
en la década de 1990. En realidad, el Perú se había alineado con los poderes económicos globales y, especialmente, con las políticas económicas de los Estados Unidos y los países europeos occidentales (Klein, 2007).

En este nuevo ambiente político y económico, una serie de reformas en la educación superior generaron la posibilidad de un incremento en el número de arqueólogos y arqueólogas peruanos. Sin embargo, también supuso el incremento de su orientación hacia un pensamiento más conservador con relación a posiciones más críticas como las que se observaron en universidad nacionales como San Marcos en la década de los 1980 e inicios de la década de 1990 (Bonavia y Matos, 1992). En realidad, la década de 1990 observó el desmantelamiento de la intelligentsia (sensu Gramsci) progresista en las universidades públicas, así como la potenciación de visiones más conservadoras. A su vez, en el Perú se dio el ingreso de una gran cantidad de investigadores norteamericanos y de otras nacionalidades que establecieron las escuelas teóricas principalmente vinculadas con las versiones más avanzadas del procesualismo norteamericano. Como ejemplo de la importancia de dicha tendencia teórica en la arqueología peruana, solo basta revisar el contenido de los diferentes números publicados por el Boletín de Arqueología PUCP en las últimas décadas.

Como parte de este proceso de neoliberalización de la profesionalización de la arqueología, la aparición de la denominada "arqueología de contrato", sin duda, generó un nuevo fenómeno profesional y metodológico dentro de la disciplina. Ahora muchos arqueólogos y arqueólogas, sobre todo de las nuevas generaciones, podían dedicarse a trabajar y obtener una buena remuneración sin necesidad de formarse en la investigación arqueológica y, más bien, prestando servicios técnicos para resolver problemas vinculados con la gestión del patrimonio cultural.

Asimismo, el crecimiento de la burocracia estatal relacionada con el patrimonio cultural y, finalmente, la posibilidad de contar con un Ministerio de Cultura generó un espacio para la inclusión de profesionales en arqueología en la estructura estatal. Nunca tantos arqueólogos y arqueólogas peruanos habían trabajado en agencias del Estado que se dedicaban a la gestión y protección del patrimonio cultural en el Perú. Visto desde la perspectiva de que la investigación arqueológica pura es mínimamente financiada por las entidades estatales peruanas y que tenemos cerca de 1900 arqueólogos y arqueólogas colegiados en el país, estamos realmente ante un cambio sustancial en la for- 
ma en la que se hace la arqueología, sobre todo si la comparamos con la del siglo pasado.

Finalmente, otro pequeño grupo de arqueólogos y arqueólogas pudo afiliarse a instituciones de investigación principalmente de universidades extranjeras para poder desarrollar su carrera en la arqueología. Como consecuencia de ello, muchos jóvenes arqueólogos y arqueólogas han podido acceder a estudios de posgrado y han posibilitado su formación dentro de escuelas teóricas de otros lugares del mundo y su posterior aplicación en sus investigaciones en su país de origen. La creciente participación de arqueólogos y arqueólogas peruanos en reuniones académicas de la especialidad en los Estados Unidos y Europa es un buen pulso de la inclusión de investigadores peruanos en el "sistema-mundo" arqueológico, tomando prestado el concepto desarrollado por Inmanuelle Wallerstein.

Como veremos a continuación, arqueólogos y arqueólogas peruanos y extranjeros han concentrado sus esfuerzos en explorar y explicar los fenómenos sociales prehispánicos tomando en cuenta dichas posibilidades para la investigación y, sobre todo, la atracción inherente a ciertos problemas de investigación arqueológica.

\section{Un panorama de las teorías arqueológicas en el Perú contemporáneo}

En este artículo se realiza un esbozo de la teoría arqueológica generada y aplicada en la arqueología peruana en las últimas dos décadas. Para ello, se utilizan los recientes trabajos de arqueólogos y arqueólogas peruanos y extranjeros en las principales áreas geográficas donde estos se ha desarrollado con mayor intensidad. Como veremos a continuación, el desarrollo y aplicación de teorías arqueológicas se presenta desigual para el territorio peruano. Así, debido al importante trabajo arqueológico realizados desde finales de la década de 1980, la costa norte del Perú (departamentos de La Libertad y Lambayeque) es, de lejos, el área más beneficiada con el desarrollo y aplicación de importantes contribuciones teóricas.

Adicionalmente, dado el evidente centralismo del Estado peruano, será en Lima donde se generen importantes aproximaciones teóricas en la arqueología peruana. Al existir tres universidades con escuelas de Arqueología, disponer de un importante número de arqueólogas y arqueólogos profesionales y estudiantes de pregrado y posgrado, encontrarse las principales agencias del 
Estado relacionadas con el patrimonio cultural que también generan explicaciones y trabajos arqueológicos, al ser el lugar donde se realizan las principales reuniones académicas y conferencias, y localizar otro importante número de instituciones privadas de investigación vinculadas con la arqueología, esta ciudad ha aportado considerablemente a la incorporación de la teoría en la práctica arqueológica.

Aunque con menor desarrollo en cuanto a la incorporación de arqueólogos y arqueólogas con publicaciones con desarrollo teórico, áreas geográficas como la costa sur también han contribuido en este despliegue, especialmente, en los departamentos de Ica y Moquegua (Dulanto y Bachir Bacha, 2017; Tantaleán y Stanish, 2017; Sakai et al., 2014; Bachir Bacha y Dulanto, 2013; Korpisaari y Chacama, 2012; Reindel y Wagner, 2009; Ziółkowski et al., 2009; Owen y Goldstein, 2001). Por su parte, la sierra sur, teniendo a Cusco como principal ciudad y antigua capital de los incas, ha desarrollado tímidamente algunas explicaciones arqueológicas a pesar de la gran concentración de yacimientos arqueológicos. Otro espacio de importancia para las aplicaciones teóricas se encuentra en Ayacucho y la causa es que muy cercana a la ciudad de Huamanga, capital del departamento y donde existe una importante escuela de Arqueología en la Universidad Nacional San Cristóbal de Huamanga, floreció la ciudad prehispánica de Huari, capital del Imperio wari. En el caso de Arequipa, al haber desaparecido en 1999 la escuela de Arqueología de la Universidad Católica de Santa María, se perdió una importante tradición de investigadores locales. Afortunadamente arqueólogos y arqueólogas de las misiones polacas en el Perú (Wołoszyn et al., 2019; Ziółkowski et al., 2009) y otros investigadores como el equipo liderado por Justin Jennings y Willy Yépez (2012) han llenado ese vacío del trabajo arqueológico en la zona.

Por su parte, la sierra norte, principalmente en el departamento de Cajamarca, ha quedado postergada debido a una falta de interés de los arqueólogos y arqueólogas nacionales, a pesar de que en las últimas décadas existen trabajos importantes como los de la misión japonesa enfocados en el periodo Formativo (Kaulicke y Onuki, 2009, 2008; Onuki e Inokuchi, 2011). No obstante, es necesario reconocer otras contribuciones para periodos prehispánicos posteriores (Toohey, 2011). Asimismo, los sitios de la sierra de La Libertad, concretamente los relacionados con la formación social Huamachuco, recibieron el interés de arqueólogos y arqueólogas norteamericanos (por ejemplo: John y Theresa Topic, 2000). No es posible dejar de mencionar aquí a los trabajos en el sitio de Chavín de Huántar, enclavado en el callejón de 
Conchucos, en el departamento de Áncash, donde una tradición de arqueólogos y arqueólogas, siguiendo la estela del mismo Tello, ha desarrollado una investigación arqueológica importante y sobre la que comentaremos sus aportes teóricos más adelante. En esa misma área, vale la pena mencionar los trabajos de George Lau (2012) enfocados en la sociedad Recuay, los cuales han generado aproximaciones teóricas innovadoras en la arqueología peruana.

Por su parte, en la sierra central se ha observado un exiguo desarrollo en la explicitación de la teoría arqueológica aplicada a las investigaciones. Todo ello, a pesar de que lugares como el valle del Mantaro fueron un "laboratorio" de investigación arqueológica en la década de 1970 y 1980 para el desarrollo de trabajos pioneros como el Upper Mantaro Archaeological Research Project (UMARP), fuertemente influenciados por el paradigma procesualista. En la actualidad, salvo algunas investigaciones esporádicas de arqueólogos y arqueólogas peruanos, no existe mayor contribución de trabajos con algún tipo de propuesta teórica más allá de la descripción de los restos arqueológicos.

El altiplano de la cuenca del Titicaca y que, para el territorio peruano, se refiere al departamento de Puno, también ha sido objeto de contados esfuerzos en el desarrollo teórico dentro de la investigación arqueológica. Allí se puede establecer que principalmente la posición teórica más importante desarrollada en la investigación arqueológica es la procesualista, pero que ha sido sofisticada con aportes de otras perspectivas teóricas contemporáneas (Aldenderfer, 2012; Klarich, 2005; Stanish, 2003).

Finalmente, observamos un escaso desarrollo teórico en los estudios arqueológicos de la Amazonia peruana. Salvo algunos trabajos importantes realizados en la ceja de selva, específicamente en el departamento de Amazonas (Church y Guengerich, 2017; Ruiz Estrada, 2010; Schjellerup, 2009; Kauffmann y Ligabue, 2003), no existen proyectos de investigación arqueológica en gran parte de la selva baja. Una de las posibles causas de la poca relevancia que se le concede a esta área geográfica peruana tendría que ver no solamente con la baja visibilidad de los sitios arqueológicos, sino también con una perspectiva instalada en la investigación peruana sobre la necesidad de realizar hallazgos extraordinarios vinculados con la riqueza y monumentalidad de las sociedades del pasado, cuestión que desalienta a muchos investigadores donde las condiciones de vida, traslado, estadía y trabajo son difíciles y la recompensa en términos de prestigio es menor. Aun así, recientes trabajos arqueológicos de "arqueología de contrato", impulsados por las actividades de extracción petrolera y minera, han posibilitado la presencia 
de arqueólogos y arqueólogas. Sin embargo, la literatura disponible en la actualidad es mínima y carece de una fuerte orientación hacia alguna teoría arqueológica reconocible. Sobre todo, se trata de trabajos de índole descriptiva.

Así, para no abundar en lo que terminaría siendo una historia de la investigación arqueológica en el Perú contemporáneo y su relación con las teorías arqueológicas presentes, en este articulo hemos propuesto una serie de temas de investigación y proyectos arqueológicos que combinan importantes sitios arqueológicos y/o zonas arqueológicas y los temas vinculados a la explicación de su existencia y desarrollo social. De esta manera, esperamos lograr un panorama de la teoría arqueológica en el Perú.

Tomando en cuenta lo anterior y siendo conscientes de la manera desigual en que se ha incorporado la teoría arqueológica por los investigadores en el territorio peruano en las dos últimas décadas, en este artículo nos enfocaremos de manera cronológica en los siguientes temas y sus implicancias teóricas:

- El Norte Chico y el periodo Arcaico Tardío

- Chavín de Huántar y el Horizonte Temprano

- La costa norte y la sociedad moche

- Huari y el fenómeno imperial andino

- Cusco y los estudios incaicos.

Como mencionamos previamente, en este artículo áreas geográficas como la costa sur, el altiplano circum-Titicaca, la sierra central, la sierra norte y sus fenómenos sociales pasados no serán abordados. A los lectores interesados, podemos remitirlos a textos que han profundizado esos temas previamente (Dulanto y Bachir-Bacha, 2017; Vega-Centeno, 2017; Bachir-Bacha y Dulanto, 2013; Flores y Tantaleán, 2013) y a recientes síntesis de la arqueología peruana (Malpass, 2016; Moore, 2014; Quilter, 2014; Silverman e Isbell, 2008). Más bien, complementaremos este articulo con otros temas que han sido motivo de interés reciente y que han implicado o implicarán el desarrollo y aplicaciones de teorías arqueológicas (etnoarqueología, arqueología colonial y/o histórica, arqueología de la muerte, arqueología del paisaje, estudios de género y/o feministas, estudios decoloniales y subalternos, nuevos materialismos, ontologías andinas y entanglement).

Para finalizar, comentaremos sobre cuáles son los temas que no se han teorizado lo suficiente o deberían comenzar a hacerse de manera más profunda (arqueología de las sociedades cazadoras-recolectoras, arqueología de la unidad doméstica, arqueología industrial, arqueología urbana, arqueología de los 
desaparecidos y la violencia reciente, etc.). El objetivo es que se pueda tomar en cuenta estas aproximaciones teóricas no solamente porque estén de moda o sean novedosas sino, principalmente, para llenar vacíos en la comprensión de fenómenos significativos socialmente en la arqueología peruana.

\section{Principales áreas, fenómenos sociales y tendencias arqueológicas en la arqueología del Perú reciente}

\section{El Norte Chico y el periodo Arcaico Tardio}

Dos grandes proyectos arqueológicos cambiaron la forma de ver la arqueología de los valles del denominado Norte Chico: el Proyecto Arqueológico del Norte Chico (PANC), liderado por Jonathan Haas y Winifred Creamer, y el Proyecto Caral (PEACS), dirigido por Ruth Shady. En el caso del PANC, sus directores Haas y Creamer (2006, p. 746) han hecho explícito que su perspectiva teórica es la del procesualismo, pero a la que recientemente se le han incorporado algunos elementos teóricos posprocesuales (Haas y Creamer, 2012). Sus explicaciones del fenómeno monumental generado en el Norte Chico durante el periodo Arcaico Tardío (3000-1800 a. C.) plantean que estaríamos ante el surgimiento de "sociedades complejas", quizá en el umbral de sociedades de tipo "jefatura", que habrían evolucionado desde sociedades más simples. Se expresa la capacidad de los líderes para organizar la economía de subsistencia con base en la agricultura.

Por su parte, Ruth Shady (2006a, 2006b) ha seguido a lo largo de sus diferentes publicaciones una aproximación histórico-cultural con algunos elementos tomados del marxismo. En su caso, la arqueóloga peruana prefiere plantear que Caral fue una suerte de "cultura matriz de la civilización andina", recordando a las propuestas de Tello con respecto a Chavín. Sin embargo, conceptos como clases sociales y Estado, inspirados en una ontología marxista, están presentes en sus explicaciones arqueológicas (Shady et al., 2015, pp. 8-17).

Una tercera propuesta procesualista, aunque con elementos posprocesuales, se puede reconocer en las publicaciones de Rafael Vega-Centeno (2017, 2010). En su caso, el ritual encarnado principalmente en la arquitectura sería un elemento importante para el surgimiento de sociedades complejas tempranas y, especialmente, la existencia de una serie de comunidades en esta región que se encontraban en competencia. Vale decir, en los valles del Norte Chico 
una serie de comunidades con diferentes niveles de complejidad social coexistieron, un escenario en el que el poder político iba fluctuando y no se llegó a constituir una verdadera integración política.

\section{Chavín de Huántar y el Horizonte Temprano}

Además del viejo debate sobre el origen y naturaleza de Chavín, que se puede remontar al mismo Julio César Tello (1943), en la actualidad existen dos grandes propuestas para la explicación de la existencia de Chavín de Huántar: la de Richard Burger y la de John Rick (Conklin y Quilter, 2008). Ambas propuestas desarrolladas por dichos investigadores norteamericanos, plantean escenarios diferentes con respecto al surgimiento y reproducción de las elites de Chavín. La propuesta de Burger, basada en sus trabajos en la década de 1970 en el sitio mismo, propone una perspectiva más cercana al establecimiento de un "ciudad-Estado" o una "jefatura compleja" en Chavín de Huántar. Su propuesta principalmente se desarrolla desde una perspectiva teórica históricocultural que está matizada con elementos procesuales y neomarxistas (Burger 2014, 2008).

Por su parte, la propuesta de John Rick (2013), procedente de una matriz teórica procesual, establece una perspectiva también neoevolucionista combinada con conceptos como "ritual", "liderazgo", "autoridad" y "prestigio" (Rick, 2015, 2008). Así, para Rick, los líderes religiosos de Chavín de Huántar utilizaron estrategias psicológicas y chamánicas para controlar a los grupos sociales que se relacionaban con este centro ceremonial. Su propuesta es que Chavín fue una "sociedad compleja", una versión un poco más matizada de procesualismo. Adicionalmente, la propuesta marxista de Lumbreras (1989), a pesar de su antigüedad, sigue siendo influyente y, por ejemplo, aparece matizada en la propuesta de Rick.

Además de la investigación en el sitio mismo de Chavín de Huántar, otros investigadores, muchos de ellos estudiantes de Burger, han extendido sus investigaciones a otras zonas de los Andes centrales relacionadas con el fenómeno Chavín y el Horizonte Temprano. De esta manera, sitios como el complejo Caballo Muerto en el valle de Moche (Nesbitt, 2012), Campanayuq Rumi en Ayacucho (Matsumoto, 2010), Atalla en Huancavelica (Young, 2017) y Huayurco en la ceja de selva en Jaén (Clasby, 2014) también han sido investigados. En estas investigaciones, los autores combinan elementos teóricos del historicismo cultural, procesualismo y posprocesualismo. 


\section{La costa norte y la sociedad moche}

De lejos, la región geográfica peruana con mayor cantidad de investigaciones y publicaciones es la costa norte y, en especial, las investigaciones relacionadas con la sociedad moche. Desde las propuestas histórico-culturales y evolutivas de Rafael Larco Hoyle en la primera mitad del siglo XX, la idea de un Estado moche ha permanecido en la mente de investigadores e investigadoras nacionales y extranjeros. Sin embargo, desde 1987 en adelante, una importante cantidad de investigaciones en la costa norte ha generado tal cantidad de datos arqueológicos que las viejas propuestas de Larco Hoyle han tenido que ser naturalmente cuestionadas (Castillo 2013, p. 182; Chapdelaine, 2010). En general, la arqueología de la costa norte ha experimentado un crecimiento en el número de voces de arqueólogos y arqueólogas peruanos y extranjeros que tienen algo que decir con respecto a los Moche (Castillo et al., 2008; Uceda y Mujica, 2003; Uceda y Mujica, 1994). Sin embargo, el procesualismo practicado por investigadores extranjeros parece dominar fuertemente el escenario teórico hasta la actualidad (Quilter y Castillo, 2010; Millaire y Morlion, 2009; Castillo et al., 2008; Uceda y Mujica, 2003;). Asimismo, en los últimos años han surgido propuestas explicativas inspiradas en elementos teóricos tomados del posprocesualismo (Quilter y Koons, 2012; Swenson, 2012). En paralelo, arqueólogos y arqueólogas peruanas, desde visiones fundamentadas en el historicismo cultural con algunos préstamos teóricos del procesualismo, también han tratado de explicar el mundo moche (Castillo et al., 2008; Millaire y Morlion, 2009; Uceda y Mujica, 2003). Asimismo, una fuerte inspiración de la historia del arte, especialmente sobre el estudio iconográfico, sigue estando muy presente en la arqueología moche (Castillo, 2013, p. 175).

En el caso peruano, uno de los líderes de los estudios de la sociedad moche, Santiago Uceda, quien investigó en el importante sitio de Huacas de Moche, desarrolló explicaciones basadas en el historicismo cultural combinadas con algunos elementos procesualistas, marxistas y posprocesualistas (Uceda 2018, 2010; Uceda y Rengifo. 2006). Por su parte, Luis Jaime Castillo (2010, 2003), quien ha investigado intensivamente el sitio de San José de Moro, ha utilizado marcos teóricos más relacionados con los estudios procesualistas con influencias del posprocesualismo. 


\section{Huari y el fenómeno imperial andino}

La sociedad wari, uno de los Estados prehispánicos más importantes de la sierra sur del Perú, ha sido sujeto de interpretaciones teóricas desde Julio C. Tello en adelante. A pesar de ello, desde los trabajos de William Isbell en la década de 1980, o las investigaciones de grupos de arqueólogos ayacuchanos durante esa misma década, se puede apreciar que a nivel teórico se han conservado los elementos fundamentales en las propuestas de la explicación de la naturaleza y dinámica del sitio y su expansión. En la actualidad, el debate sigue manteniendo las ideas básicas surgidas en esa época como la propuesta de Isbell (2018) dentro de una matriz teórica procesual con elementos posprocesuales y la de Lumbreras (2007), principalmente marxista, aunque con herencias teóricas del historicismo-cultural.

Debido a la naturaleza expansiva y su impronta en diversas regiones de los Andes centrales como la costa y sierra del Perú, diferentes arqueólogos y arqueólogas que han investigado en dichas zonas han generado propuestas vinculadas al carácter del Estado wari (Isbell et al., 2018; Giersz y Makowski, 2013; Bergh, 2012; Castillo y Jennings, 2012; Jennings, 2011; Kaulicke e Isbell, 2001, 2000). Un rápido vistazo a esa legión de arqueólogos y arqueólogas plantea que, en general, sus perspectivas teóricas surgen principalmente de matrices teóricas procesualistas, aunque también incorporan elementos del historicismo-cultural, marxismo y posprocesualismo.

\section{Cusco y los estudios incaicos}

La sociedad inca posee una importante documentación histórica que permite generar aproximaciones teóricas más matizadas. En general, la aproximación ha sido más histórica que arqueológica desde los primeros intentos explicativos de Luis E. Valcárcel y, especialmente, los de John Rowe. En la actualidad, la producción científica sobre los incas es inmensa y se podría decir que casi todas las escuelas teóricas han estado y siguen presentes en la explicación de este fenómeno social prehispánico. Aunque vale la pena mencionar que las teorías procesualistas siguen siendo las más prominentes, especialmente por la gran cantidad de arqueólogos y arqueólogas norteamericanas que se han dedicado al estudio de esa sociedad (Kaulicke et al., 2004, 2003, 2002). Como vimos, esta es una tradición que se podría remontar a la época del desarrollo del UMARP. Adicionalmente, vale la pena mencionar que una serie 
de perspectivas en los estudios de los incas desde la "arqueología simétrica" u ontologías andinas también han irrumpido en los estudios incas (Bray, 2015).

Por la parte peruana, en los últimos años el programa Qhapaq Ñan ha posibilitado el conocimiento extensivo y detallado de asentamientos y caminos incas como nunca. Es notorio que, gracias a sus principales investigadores, una importante influencia procesualista norteamericana se ha deslizado en la explicación de los incas. Especialmente el uso de tecnologías avanzadas en la relevación de datos y una analítica cuantitativa, desde un cientificismo muy cercano a la revolución procesualista de la década de 1970, se puede percibir en los nuevos estudios. ${ }^{3}$ Aun así, dada la combinación de diferentes especialistas con diferentes formaciones teóricas y metodológicas, los estudios del proyecto Qhapaq Ñan plantean un escenario teórico muy diverso.

A la vez, dicho desarrollo desplegado por parte del programa Qhapaq Ñan ha posibilitado que otros arqueólogos y arqueólogas peruanos se interesen y se mantengan en la investigación, generándose una verdadera explosión en los estudios sobre los incas. Importantes revistas como Cuadernos de Investigación del Qhapaq Ñan, Inka Llaqta o Haucaypata dan cuenta de dicho avance en las investigaciones sobre los incas y pueden ser un importante pulso de las posiciones teóricas contemporáneas. Aun con todo, la perspectiva etnohistórica sigue siendo la más importante a la hora de explicar la formación social incaica.

\section{Otros temas teóricos recientemente desarrollados en la arqueología peruana}

Además de los grandes temas y zonas geográficas en las cuales los estudios arqueológicos han impactado profundamente y han dejado una importante impronta en la literatura arqueológica, en esta sección se señalan una serie de temas que han sido estudiados recientemente en el Perú y que han incorporado propuestas teóricas novedosas y que, en los próximos años, seguramente seguirán ampliándose y profundizándose. Asimismo, en estas nuevas aproximaciones teóricas, las nuevas metodologías y tecnologías han ofrecido sustento para la comprobación de sus hipótesis y explicaciones sociales.

3 Al respecto, véase Chacaltana y et al. (2017), en especial Covey et al. (2017) y Wernke et al. (2017). 


\section{Etnoarqueología}

La etnoarqueología como subdisciplina dentro de la arqueología fue definida como tal en la década de 1960 en los Estados Unidos, dentro de la arqueología procesualista, y tuvo como principal impulsor a Lewis Binford (Politis, 2004, p. $6 ; 2002$, p. 73). En el caso del Perú, previamente a este desarrollo teóricometodológico existió una importante tradición de estudios etnográficos y, como ejemplo de este campo vinculado a la arqueología, podríamos señalar los trabajos de Donald Collier (1967[1959]), Warren DeBoer y Donald Lathrap (DeBoer y Lathrap 1979; DeBoer 1974) o los de Kent Flannery, Joyce Marcus y Robert Reynolds (1989). Más adelante, otros trabajos explícitamente etnoarqueológicos son los de Melissa Hagstrum (1989), Isabelle Druc (1996), Lawrence Kuznar $(1995,1990)$ o los de Bill Sillar (2000), entre otros (también ver Sillar y Ramón, 2016). Asimismo, la existencia de una importante corriente antropológica vinculada con los pueblos productores de cultura material en los Andes ha permitido su desarrollo (Arnold, 1993; Allen, 1988; Isbell, 1978). En la actualidad, existen algunos trabajos como los que continúa realizando Isabelle Druc (2013) o los más recientes de Gabriel Ramón (2013) que han permitido conocer más en detalle las producciones artesanales, especialmente cerámica, y poder utilizarlas como analogías para la explicación de los contextos arqueológicos del pasado.

\section{Arqueología colonial e histórica}

Desde sus inicios y durante gran parte del siglo XX, la arqueología andina ha sido principalmente prehispánica. Más allá de que la etnohistoria ha socorrido a los arqueólogos y arqueólogas para la explicación de fenómenos prehispánicos y que existieron algunos estudios pioneros sobre las épocas históricas (Cárdenas, 1973, 1971, 1970; Rice y Smith, 1989), recién en estos últimos años se han generado un grupo importante de investigadores enfocados en las épocas históricas. En ese sentido, la época colonial temprana ha sido beneficiada por una serie de estudios arqueológicos (Traslaviña et al., 2016a, 2016b; Quilter, et al., 2010; Rice, 2014, 2012; Wernke, 2013; Bauer y Coello, 2007). En algunos de estos estudios, se puede apreciar que las perspectivas teóricas se vinculan a un procesualismo sofisticado que incluye muchos elementos posprocesuales (por ejemplo: VanValkenburgh, 2016; Wernke, 2016). Pero, sobre todo, se puede observar una importante incorporación de teorías socia- 
les arqueológicas (principalmente posprocesuales), antropológicas, sociológicas e históricas contemporáneas (por ejemplo: Chase 2016; Murphy y Boza 2016). No obstante este avance en los estudios de época históricas tempranas, aún quedan por desarrollar más investigaciones arqueológicas enfocadas en contextos arqueológicos del siglo XIX y XX e, incluso, en tiempos contemporáneos (González-Ruibal, 2019).

\section{Arqueología de la muerte}

A pesar que existe una tradición de estudios bien desarrollada de estudios sobre contextos funerarios en los Andes centrales (Dillehay, 1995), recién en las últimas décadas ha surgido una serie de nuevos enfoques teóricos explícitos con relación al estudio de la muerte. Así, se han dado investigaciones que mediante metodologías novedosas ahora pueden plantear escenarios muchos más complejos que los de décadas atrás. De este modo, además de un desarrollo especializado en la bioantropología, la revolución del ADN y de los análisis de isotopos estables han permitido explicar fenómenos sociales sobre la base de contextos funerarios de manera mucho más precisa y detallada. Estudios novedosos de bioantropología como los de John Verano (2016) o Tiffiny Tung (2012), entre otros, permiten comprender fenómenos relacionados con los contextos funerarios y restos de sacrificios humanos. Así también, los estudios de ADN, en especial del mitocondrial, han permitido entender las dinámicas poblacionales, la movilidad de los grupos sociales en el territorio, las descendencias y las relaciones sociales dentro y afuera de las comunidades prehispánicas (Fehren-Schmitz et al., 2011; Lewis et al., 2007; Shimada et al., 2004;). Asimismo, importantes estudios incorporando análisis de isotopos de estroncio y oxígeno han permitido comprender los orígenes y los desplazamientos de individuos en el paisaje prehispánico andino (Knudson et al., 2009; Knudson et al., 2004).

Más allá de dichos avances metodológicos, en muchos de los casos, la perspectiva teórica dominante en la arqueología de la muerte en el Perú es la procesualista, aunque muchas veces incluyendo elementos posprocesualistas (Klaus y Toyne, 2016: Eeckhout y Owens, 2015a [p. 7], 2015b; Shimada y Fitzsimmons, 2015). Adicionalmente, en los últimos años algunas propuestas explicativas inspiradas, primordialmente en el posprocesualismo y en el "giro ontológico" en arqueología, han comenzado a aparecer en los estudios 
relacionados con la muerte (Muro et al., 2019; Spence-Morrow y Swenson, 2019).

\section{Arqueología del paisaje}

La arqueología del paisaje es un tema de estudio que ha tenido un importante desarrollo en los Estados Unidos, Inglaterra y para el mundo iberoamericano, especialmente en España (David y Thomas, 2008; Ashmore y Knapp, 1999; Criado-Boado 1999). En el Perú, uno de los primeros artículos desarrollando explícitamente esta perspectiva fue el de Peter Kaulicke y asociados (2003). Más adelante, una serie de esfuerzos han sido realizados para incorporar el paisaje dentro de la explicación de los fenómenos sociales andinos (Lane y Herrera 2005; Herrera 2003). La perspectiva fenomenológica, principalmente la desarrollada en arqueología por Christopher Tilley (1994), también se incorporó al estudio de los paisajes y espacios sociales andinos (Nair, 2015; Isbell y Vranich, 2004). Recientemente, un volumen editado en el Perú por Luis Flores Blanco (2018) reúne una importante cantidad de capítulos relacionados con esa temática. Sin embargo, podemos ver en esa misma publicación que, para el caso peruano, varias perspectivas teóricas cohabitan en dicha aproximación al estudio del paisaje y, muchas veces, cada una de ellas tiende a ser teóricamente ecléctica (por ejemplo: Farfán, 2018; Flores, 2018; Herrera, 2018).

\section{Arqueología de género y/o feminista}

En parte como respuesta a una situación de androcentrismo en la sociedad y academia arqueológica peruana, un grupo de investigadoras ha comenzado a exigir su visibilidad e inclusión dentro de las explicaciones del pasado. Aunque ya Irene Silverblatt (1987) y Joan Gero $(1999,1992)$ expresaban su influencia de las teorías feministas, solo será en los últimos años cuando estudios explícitamente feministas o de género se han incorporado a la literatura arqueológica peruana (Artzi, 2019; Chacaltana, 2019; Santana, 2019; Tavera, 2019). Debido a que la arqueología feminista y de género tiene un importante desarrollo no solamente en los Estados Unidos sino especialmente en Europa, las maneras en que este enfoque se están desarrollando en el Perú todavía no permiten establecer cuáles son sus orientaciones teóricas específicas. En este punto, las aproximaciones señaladas parecen poseer una influencia muy 
importante de la arqueología feminista norteamericana de la década de 1970 en adelante (Conkey y Spector, 1984), pero también con elementos teóricos tomados de las arqueologías posprocesuales y marxistas.

\section{Arqueologías decoloniales y subalternas}

En gran medida, gracias a las reuniones de Teoría Arqueológica de América del Sur (TAAS) y sus consecuentes publicaciones, la arqueología sudamericana ha incorporado una serie de desarrollos relacionados con la teoría decolonial, inspirada por intelectuales como Enrique Dussel, Walter Mignolo o Aníbal Quijano (Verdesio, 2014). Como vimos, a pesar de que el Perú es uno de los que menos arqueólogos y arqueólogas aporta a dichas reuniones, su exposición a dichas perspectivas teóricas ha impactado en sus ideas. En el presente, los estudios sobre otras narrativas, la deconstrucción de los discursos oficiales y la arqueología de los grupos subalternos está formando una importante manera de ver las explicaciones arqueológicas e históricas en el Perú.

\section{Nuevos materialismos y entanglement}

Como señalamos, en la década de 1990 y, especialmente, a comienzos del siglo XX, se dio un importante desarrollo en los estudios de cultura material (Miller, 2005; Miller y Tilley, 1996). Asimismo, gracias a la inspiración de Bruno Latour se desarrolló una "arqueología simétrica" en Europa y los Estados Unidos (González-Ruibal, 2007; Olsen, 2007; Shanks, 2007; Witmore, 2007). En el Perú, esta influencia se dio tardíamente y de manera específica en algunos arqueólogos y arqueólogas expuestos a esos debates, especialmente en los Estados Unidos e Inglaterra. De entre esos avances más recientes, algunos arqueólogos y arqueólogas peruanos, que justamente estudiaron en la Universidad de Stanford con Ian Hodder, han desarrollado una perspectiva relacionada con su propuesta de entanglement (Hodder, 2012) y la han aplicado a casos arqueológicos andinos (Fernandini, 2018, 2016). De hecho, Hodder visitó al Perú hace unos años y explicó su, entonces, nueva perspectiva en Lima. Sin embargo, su influencia parece haber sido mínima en una ecología arqueológica dominada por los estudios histórico-culturales y procesualistas. 
Perspectivismo amerindio y ontologías andinas

Finalmente, con el "giro ontológico" en la antropología y arqueología (Alberti 2016; Viveiros de Castro 2010; Descola, 2005; Kohn, 2015) muchos arqueólogos y arqueólogas, especialmente norteamericanos y ahora peruanos, han comenzado a explorar las ontologías andinas como forma de aproximarse a las sociedades del pasado (Lozada y Tantaleán, 2019; Fernandini y Muro, 2018; Bray, 2015; Weismantel, 2015, 2013; Lau, 2012; Sillar, 2009). En el medio académico peruano esto ha sido impulsado también porque existen grupos de estudios filosóficos como Chaupi Atoq que han analizado sistemáticamente el Manuscrito de Huarochirí (Depaz, 2015), una importante obra de principios del siglo XVII que permitiría acceder a la cosmovisión indígena y prehispánica. Desde la misma arqueología peruana, varios investigadores han utilizado dicho manuscrito para comprender las percepciones andinas del paisaje y la materialidad (Chase, 2016; Bray, 2015).

\section{Temas por desarrollar en la arqueología peruana}

Para finalizar este artículo, en esta sección señalamos un conjunto de temas que han sido escasamente explorados y que pensamos deberían ser desarrollados e integrados a la arqueología peruana como parte de su práctica y de su debate teórico contemporáneo.

\section{Arqueología de las sociedades cazadoras-recolectoras}

Los Andes peruanos han tenido una importante contribución con respecto al conocimiento del poblamiento temprano y de las sociedades cazadores recolectoras o del periodo precerámico. Estudios como los de Frederic Engel, Thomas Lynch, Richard McNeish, Augusto Cardich o James Richardson III fueron pioneros y consistentes durante la segunda mitad del siglo XX (Ortiz, 2017). Sin embargo, a comienzos del siglo XXI se pueden contar con los dedos de la mano a los especialistas interesados en la investigación de este extenso periodo. Si bien Duccio Bonavia formó un grupo de estudiante peruanos, este no parece haber llegado a consolidarse. Lo mismo se puede aplicar a la escuela francesa liderada en el Perú por Danielle Lavallée y Claude Chauchat. Por otra parte, arqueólogos como Daniel Sandweiss, 
Mark Aldenderfer, Tom Dillehay, Kurt Rademaker, entre otros, han generado y conducido sus propios proyectos de investigación sobre el tema, especialmente influenciados por la teoría procesualista. A estos recientes estudios se les puede añadir los últimos de Danièle Lavallée y Michèle J ulien (2012). Pese a los avances llevados por colegas extranjeros, pocos arqueólogos y arqueólogas peruanas han desarrollado sus propios proyectos de investigación y, menos aún, han desarrollado una propuesta propia influenciada por otras teorías al uso. Excepciones son los trabajos de Elmo León (2007) y Juan Yataco (2013), con publicaciones enfocadas en análisis de colecciones, o los de Luis Salcedo (2019), con datos arqueológicos procedentes principalmente de trabajos de "arqueología de contrato". Pero, en general, las aproximaciones empiricistas, descriptivas y/o funcionalistas son las que siguen predominando en los escasos estudios sobre esta temática (Ortiz, 2017; Kaulicke y Dillehay, 2011).

\section{Arqueología de la unidad doméstica}

Desde finales de la década de 1980 se dio un impulso a la "arqueología de la unidad doméstica" en el Perú (Aldenderfer, 1993; Stanish, 1989; Bawden, 1982). Sin embargo, pocos estudios se han enfocado específicamente en este tipo de contextos arqueológicos (Nash, 2009). Debido a que existe una fuerte tendencia a estudiar contextos de elites, las unidades domésticas han sido marginadas en las reconstrucciones de las sociedades prehispánicas. Su potencial es importante para reconocer a los grupos productores y/o dominados de las sociedades prehispánicas.

\section{Arqueología industrial y arqueología urbana}

Como señalábamos, a pesar de que hay un desarrollo muy reciente de la arqueología histórica, aún quedan por trabajar en las arqueologías de nuestra contemporaneidad. A pesar de que muchos de esos estudios ya se han venido desarrollando en Chile, Argentina y Brasil, en el Perú aún no existe una significativa cantidad de arqueólogos y arqueólogas interesados en los periodos históricos recientes. Se torna de inmediata necesidad debido a que los estudios históricos, con todas las virtudes que puedan tener, no se enfocan directamente en la cultura material o los cuerpos de los sujetos de dichas sociedades. 


\section{Arqueología de los desaparecidos y la violencia reciente}

Finalmente, un grupo de investigadores formados en arqueología forense han generado un pequeño colectivo interesado en la violencia durante el conflicto de las décadas de 1980 y 1990 (Estrada y Mayta, 2020; Baraybar y Mora, 2014). En ese sentido, esta investigación persigue la recuperación de la memoria histórica, en especial el reconocimiento de la violencia cometida por los grupos subversivos y del Estado peruano cuando se vio involucrado. Aunque un conjunto de dichos investigadores estuvo influenciado originalmente por la arqueología social impulsada por Luis G. Lumbreras, en la actualidad siguen procedimientos estándares de la antropología y arqueología forense y están más orientados hacia la búsqueda de justicia social, especialmente de la reivindicación las víctimas que padecieron violencia en los tiempos del conflicto interno (Baraybar y Mora, 2016, p. 468; Bolaños, 2016).

\section{Comentarios finales}

En las últimas dos décadas se ha dado un notable crecimiento en el número de investigaciones arqueológicas en el Perú. Asimismo, existe una importante cantidad de arqueólogos y arqueólogas peruanos formados en estudios de pregrado en el país y otros tantos con estudios de posgrado en el extranjero. De dicha masa crítica de estudiosos del pasado y la larga herencia de teorías arqueológicas que han convergido en los Andes, en la actualidad tenemos un importante conjunto de posicionamientos teóricos que son aplicados a la explicación de la prehistoria e historia de los Andes.

Sin embargo, también se puede apreciar que, en general, las investigaciones realizadas por arqueólogos y arqueólogas peruanos resultan en la generación y descripción de datos bajo perspectivas empiricistas e histórico-culturales. En realidad, se puede notar que muchas veces la teoría arqueológica es una cuestión que no reviste mayor relevancia para los investigadores nacionales. En el mejor de los casos, debido a su exposición directa o indirecta a investigadores extranjeros, algunos arqueólogos y arqueólogas peruanos han incorporado ciertos elementos de las teorías que utilizan sus colegas de otras partes del mundo.

Como en muchas partes de Latinoamérica, la perspectiva teórica más desarrollada y consistente en la arqueología peruana es la que se relaciona con 
las propuestas de los proyectos arqueológicos norteamericanos. Esto sucede principalmente porque dichos proyectos poseen importantes financiamientos que les permiten prolongar su permanencia y contactos con colegas peruanos. Incluso, gracias a esta dinámica y los apoyos de sus instituciones de origen, algunos de sus colegas peruanos pueden incorporarse directa o indirectamente a la academia norteamericana, principalmente de influencia procesualista. Sin embargo, en las últimas dos décadas también se aprecia el crecimiento en el número de arqueólogos y arqueólogas extranjeros con perspectivas teóricas críticas y posprocesuales.

Asimismo, aunque en los Andes centrales se desarrolló una arqueología social inspirada en el marxismo (Lumbreras 1974), en la actualidad pocos arqueólogos se adscriben a dicha perspectiva teórica. Incluso en ese reducido grupo de investigadores, un número reducido participa en verdaderos programas arqueológicos que desarrollan dicha perspectiva teórica de manera consistente. Una excepción serían los proyectos arqueológicos en el Perú liderados por investigadores procedentes de la Universidad Autónoma de Barcelona (Castro-Martínez et al., 2016; De la Torre, 2012). No obstante, la influencia de estos grupos de investigación en los arqueólogos peruanos aún es poco visible. Lo que sí es evidente es que la formación que han tenido ciertos investigadores que fueron influenciados por la arqueología social, especialmente la peruana, les ha permitido incorporarse en otros grupos de investigación en los cuales han aportado con la generación de nuevos datos o en la propuesta de prácticas novedosas relacionadas con la gestión del patrimonio cultural o la arqueología forense.

Por otra parte, aunque el posprocesualismo y los estudios de cultura material fueron trascendentales para la crítica y el giro hacia visiones más radicales de los restos materiales y las sociedades que los crearon, en el Perú dicho debate llegó tardíamente y no influyó en los investigadores nacionales en su momento de mayor desarrollo. Para cuando finalmente esta perspectiva teórica ingresó al Perú, los principales actores de dicha propuesta posprocesual ya habían retornado a teorías más científicas o habían sofisticado sus narrativas. Una hipótesis es que esto se debió a que, en su momento, los investigadores extranjeros que trabajaban en el Perú fueron ajenos/esquivos a las críticas posprocesuales de la década de 1980 y 1990. A la vez, la falta de exposición de los arqueólogos y arqueólogas peruanos a los debates arqueológicos del mundo anglosajón los privó de la posibilidad de incorporarse en tal debate. Todo ello estuvo agravado porque la literatura en la que se ventilaban dichas 
discusiones académicas apareció en lengua inglesa y no fue accesible en el Perú.

Como hemos visto en este artículo, en la actualidad el panorama teórico arqueológico peruano se encuentra densamente poblado por perspectivas teóricas ya clásicas como el historicismo-cultural, el marxismo, el procesualismo, pero también con un incremento importante en el uso de elementos teóricos surgidos a partir del posprocesualismo. Como es de esperar, la teoría arqueológica en el Perú seguirá siendo utilizada e incorporada en las diferentes y diversas investigaciones arqueológicas. Aunque la presencia de la teoría arqueológica muchas veces es invisibilizada o infravalorada, supone un elemento fundamental y significativo para comprender profundamente los fenómenos sociales del pasado en esta parte del mundo. 


\section{Referencias bibliográficas}

Alberto, B. (2015). Archaeologies of Ontology. Annual Review of Anthropology, 45, 163-179.

Aldenderfer, M. (2012). Balances y perspectivas del periodo Arcaico en la región del Altiplano. En Flores, L. y Tantaleán, H. (Eds.). Arqueología de la cuenca del Titicaca, Perú (pp. 27-39). Lima: IFEA, Cotsen Institute of Archaeology.

Aldenderfer, M. (Ed.) (1993). Domestic Architecture, Ethnicity and Complementarity in the South Central Andes. Iowa City: University of Iowa Press.

Allen, C. (1988). The Hold Life Has: Coca and Cultural Identity in an Andean Community. Washington D. C.: Smithsonian Institution.

Althusser, L. (1971). Lenin and Philosophy and Other Essays. Nueva York: Monthly Review Press.

Arnold, D. (1993). Ecology and Ceramic Production in an Andean Community. Cambridge: Cambridge University Press.

Artzi, B. (2019). La arqueología andina y la teoría de género y queer. Una propuesta de cómo entrelazarlas. En Curatola, M. (Ed.). El estudio del mundo andino (pp. 73-85). Lima: Fondo Editorial de la Pontificia Universidad Católica del Perú.

Asensio, Raúl (2018). Señores del pasado. Arqueólogos, museos y huaqueros en el Perú. Lima: Instituto de Estudios Peruanos.

Ashmore, W. y Bernard K. (Ed.) (1999). Archaeologies of Landscape. Contemporary Perspectives. Malden: Blackwell.

Bachir-Bacha, A. y Dulanto, J. (Eds.) (2013). Paracas: nuevas evidencias, nuevas perspectivas. Boletín de Arqueología PUCP, 17.

Baraybar, J. P. y Mora, F. (2014). Forensic Archaeology in Peru: Between Science and Activism. En Groen, M., Márquez-Grant, N. y Robert Janaway, R. (Eds.). Forensic Archaeology: A Global Perspective (pp. 62-77). Ámsterdam: Wiley-Blackwell.

Bauer, B. y Coello, A. (2007). The Hospital of San Andrés (Lima, Peru) and the Search for the Royal Mummies of the Incas. Fieldiana Anthropology, 39, 1-31.

Bawden, G. (1982). Community Organization Reflected by the Household: A Study of Pre-Columbian Social Dynamics. Journal of Field Archaeology, 9(2), 165-181.

Bentley, A. y Maschner, H. (2009). Introduction: On Archaeological Theories. En Bentley, A., Maschner, H. y Chippindale, C. (Eds.). Handbook of Archaeological Theories (pp. 1-7). Lanham: Rowman \& Littlefield.

Bentley, A., Maschner. H. y Chippindale, C. (Eds.) (2009). Handbook of Archaeological Theories. Lanham: Rowman \& Littlefield.

Bergh, S. (Ed.) (2012). Wari. Lords of the Ancient Andes. Londres: Thames \& Hudson. 
Bhabha, H. (1994). The Location of Culture. Londres: Routledge.

Bolaños,A. (2016). The Landscape of the Disappeared in Peru. Trialog, 118-119(3-4),18-24.

Bonavia, D. y Matos, R. (1992). Enseñanza de la arqueología en el Perú. Lima: FOMCIENCIAS.

Bourdieu, P. (1977). Outline of a Theory of Practice. Nueva York: Cambridge University Press.

Bray, T. (Ed.) (2015). Archaeology of the W'akas: Explorations of the Sacred in the PreColumbian Andes. Boudler: University Press of Colorado.

Burger, R. (2014). The Development of Early Peruvian Civilisation (2600-300 BCE). En Renfrew, C. y Bahn, P. (Eds.). The Cambridge World Prehistory (vol. 2, pp. 10751097). Cambridge: Cambridge University Press.

Burger, R. (2008). Chavín de Huántar and Its Sphere of Influence. En Silverman, H. y Isbell, W. (Eds). The Handbook of South American Archaeology (pp. 681-703). Nueva York: Springer.

Burger, R. (1989). An Overview of Peruvian Archaeology (1976-1986). Annual Review of Anthropology, 18, 37-69.

Butler, J. (1993) Bodies That Matter: On the Discursive Limits of "Sex". Londres: Routledge.

Cárdenas, M. (1973). Cerámica de transición: Huaca Palomino, valle del Rímac. Boletín del Seminario de Arqueología, 14, 30-34.

Cárdenas, M. (1971). Huaca Palomino, valle de Rímac: fragmentería vidriada fina con decoración en colores. Boletín del Seminario de Arqueología, 10, 61-67.

Cárdenas, M. (1970). Ocupación española de una huaca del valle de Lima: casa en la plataforma superior de la Huaca Tres Palos. Boletín del Seminario de Arqueología, $5,40-49$.

Castillo, L. J. (2003). Los últimos mochicas en Jequetepeque. En Uceda, S. y Mujica, E. (Eds.). Moche: hacia el final del milenio (t. II, pp. 65-123). Lima: Universidad Nacional de Trujillo/Pontificia Universidad Católica del Perú.

Castillo, L. J. (2010). Moche Politics in the Jequetepeque Valley: A Case for Political Opportunism. Quilter, Jeffrey y Luis Jaime Castillo (Eds.). New Perspectives on Moche Political Organization:83-109. Washington D. C.: Dumbarton Oaks,

Castillo, L. J. (2013). 110 años de arqueología mochica: cambios paradigmáticos y nuevas perspectivas. En Tantaleán, H. y Astuhuamán, C. (Eds.). Historia de la arqueología en el Perú del siglo XX (pp. 157-205). Lima: IFEA, IAR.

Castillo, L. J. y Jennings, J. (Eds.) (2012). Los rostros de wari: perspectivas interregionales sobre el Horizonte Medio. Boletín de Arqueología PUCP, 16. 
Castillo, L. J., Bernier, H., Lockard, G. y Rucabado Yong, J. (Eds.) (2008). Arqueología Mochica. Nuevos enfoques. Lima: IFEA, Fondo Editorial de la Pontificia Universidad Católica del Perú.

Castro-Martínez, P., Escoriza, T., González-Ramírez, A., Irazábal, S., Sáez-Sepúlveda, A. y Salazar, V. (201). Proyecto de investigación arqueológica La Puntilla: últimas aportaciones de las excavaciones en extensión en los asentamientos de El Trigal. En Actas del I Congreso Nacional de Arqueología (pp. 293-300). Lima: Ministerio de Cultura. Chacaltana, S. (2019). Mujeres e identidades de género en el Colesuyo. En Rosas, C. (Ed.). Género y mujeres en la historia del Perú (pp. 27-54). Lima: Fondo Editorial de la Pontificia Universidad Católica del Perú.

Chacaltana, S., Arkush, E. y Marcone, G. (Eds.) (2017). Nuevas tendencias en el estudio de los caminos. Lima: Ministerio de Cultura.

Chapdelaine, C. (2010). Recent Advances in Moche Archaeology. Journal of Archaeological Research, 19(2), 191-231.

Chase, Z. (2016). Pacha y presentación: La conversión colonial de Huarochirí prehistórica. Boletín de Arqueología PUCP, 21, 13-37.

Choy, E. (1979) Antropología e historia. Lima: Fondo Editorial de la Universidad Nacional Mayor de San Marcos.

Church, E. y Anna Guengerich (Eds.) (2017). ¿Qué fue Chachapoyas? Aproximaciones interdisciplinarias en el estudio de los Andes nororientales del Perú. Boletín de Arqueología PUCP, 23.

Clasby, R. (2014). Exploring Long Term Cultural Developments and Interregional Interaction in the Eastern Slopes of the Andes: A Case Study from the Site of Huayurco, Jaén Region, Peru (tesis doctoral). New Haven: Departamento de Antropología de Yale University.

Collier, D. (1967[1959]). Pottery Stamping and Molding on the North Coast of Peru. En Rowe, J. y Menzel, D. (Eds.). Peruvian Archaeology. Selected Readings (pp. 264274). Palo Alto: Peek Publication.

Conkey, M. y Spector, J. (1984). Archaeology and the Study of Gender. Advances in Archaeological Method and Theory, 7, 1-38.

Conklin, E. y Quilter, J. (Eds.) (2008). Chavin: Art, Architecture and Culture. Los Ángeles: Cotsen Institute of Archaeology, UCLA.

Covey, A., Amado, D., Tsesmeli, L. y Clark, M. (2017). Hacia una reconstrucción multidisciplinaria de la red imperial inca (Qhapaq Nan) en la región del Cusco. En Chacaltana, S., Arkush, E. y Marcone, G. (Eds.). Nuevas tendencias en el estudio de los caminos (pp. 48-71). Lima: Ministerio de Cultura. 
Criado-Boado, F. (1999). Del terreno al espacio: planteamientos y perspectivas para la arqueología del paisaje. Santiago de Compostela: Universidad de Santiago de Compostela.

Crossland, Z. y Andrew Fleming 2014 Theoretical Archaeology Group (TAG). En Smith, Claire (ed): Encyclopedia of Global Archaeology:7302-7304. Springer, New York.

David, B. y Thomas, J. (Ed.) (2008). Handbook of Landscape Archaeology. Walnut Creek: Left Coast Press.

Dark, K. (1995). Theoretical Archaeology. Ithaca: Cornell University Press.

DeBoer, W. (1974). Ceramic Longevity and Archaeological Interpretation: An Example from the Upper Ucayali, Peru. American Antiquity, 39, 335-344.

DeBoer, W. y Lathrap, D. (1979). The Making and Breaking of Shipibo-Conibo Ceramics. En Kramer, C. (Ed.). Ethnoarchaeology: Implications of Ethnography for Archaeology (pp. 102-138). Nueva York: Columbia University Press.

De la Torre, J. C. (2012). De entierros y ofrendas: un cementerio en tiempos Nasca, en el valle de Aja, Perú. Arqueología y Sociedad, 25, 89-114.

Depaz, Z. (2015). La cosmo-visión andina en el manuscrito de Huarochirí. Lima: Vicio Perpetuo Vicio Perfecto.

Descola, P. (2005). Par-Delà Nature et Culture. París: Gallimard.

Dillehay, T. (2011). La arquitectura en los espacios transitorios de la tradición Paiján. Boletín de Arqueología PUCP, 15, 145-163.

Dillehay, T. (2008). Latin American Archaeology in History and Practice. En Bentley, Alexander, Herbert Maschner y Christopher Chippindale (Eds.). Handbook of Archaeological Theories (pp. 165-185). Landham: Altamira.

Dillehay, T. (Ed.) (1995). Tombs for the Living: Andean Mortuary Practices. Washington, D. C.: Dumbarton Oaks.

Druc, I. (1996). De la etnografía hacia la arqueología: aportes de entrevistas con ceramistas de Áncash (Perú) para la caracterización de la cerámica prehispánica. Boletín del IFEA, 25(1). 17-41.

Druc, I. (2013). What is Local? Looking at Ceramic Production in the Peruvian Highlands and Beyond. Journal of Anthropological Research, 69(4), 485-513.

Dulanto, J. y Bachir-Bacha, A. (Eds.) (2017). Interacciones horizontales y verticales en la costa y sierra sur en tiempos prehispánicos. Boletín de Arqueología PUCP, 22.

Eeckhout, P. y Owens, L. (2015a). The Impossibility of Death. Introduction to Funerary Practices and Models in the Ancient Andes. En Eeckhout, P. y Owens, L. (Eds.). Funerary Practices and Models in the Ancient Andes: The Return of the Living Dead (pp. 1-11). Cambridge: Cambridge University Press. 
Eeckhout, P. y Owens, L. (Eds.) (2015b). Funerary Practices and Models in the Ancient Andes: The Return of the Living Dead. Cambridge: Cambridge University Press.

Estrada, F. y Maita, P. (2020). Forensic Archaeology and Humanitarian Context: Localization, Recovery and Documentation of Human Remains. En Parra, R., Zapico, S. y Ubelaker, D. (Eds.). Forensic Science and Humanitarian Action: Interacting with the Dead and the Living (pp. 171-182). Nueva Jersey: Wiley.

Farfán, C. (2018). Paisajes empoderados y sacralizados en la costa y sierra central de los Andes. En Flores, L. (Ed.). Lugares, monumentos, ancestros: arqueologías de paisajes andinos y lejanos (pp. 221-236). Lima: Avqi.

Fehren-Schmitz, L., Llamas, B., Tomasto, E. y Haak, W. (2011). El ADN antiguo y la historia del poblamiento temprano del oeste de Sudamérica: lo que hemos aprendido y hacia dónde vamos. Boletín de Arqueología PUCP, 15, 17-41.

Fernandini, F. (2018). Los enredos de las personas y las cosas en Cerro de Oro, Perú. Boletín de Arqueología PUCP, 24, 99-118.

Fernandini, F. (2016). From Enchantment to Entrapment: Following the Threads of Foreign Artifacts in San José de Moro. En Der, L. y Fernandini, F. (Eds.). Archaeology of Entanglement (pp. 103-124). Walnut Creek: Left Coast Press.

Fernandini, F. y Muro, L. (Eds.) (2018). Cuerpo, cosas y espacio social. Perspectivas desde la arqueología latinoamericana. Boletín de Arqueología PUCP, 24.

Flannery, K., Marcus, J. y Reynolds, R. (1989). The Flocks of the Wamani. A Study of Llama Herders on the Punas of Ayacucho, Peru. San Diego: Academic Press.

Flores, L. (2018). En la Casa de los Abuelos: producción de lugares monumentales en la cuenca del Titicaca. En Flores, L. (Ed.). Lugares, monumentos, ancestros: arqueologías de paisajes andinos y lejanos (pp. 93-117). Lima: Avqi.

Flores, L. (Ed.) (2018). Lugares, monumentos, ancestros: arqueologías de paisajes andinos y lejanos. Lima: Avqi.

Flores, L. y Tantaleán, H. (Eds.) (2013). Arqueología de la cuenca del Titicaca, Perú. Lima: IFEA/Cotsen Institute of Archaeology

Foucault, M. (1977). Discipline and Punish: The Birth of the Prison. Nueva York: Random House.

Gándara, M. (1993). El análisis de posiciones teóricas: aplicaciones a la arqueología social. Boletín de Antropología Americana, 27, 5-20.

García, J. (2012). Neo-procesualismo como renovación crítica: un ejemplo desde el paisaje. ArkeoGazte, 2, 95-112.

Gell, A. (1998). Art and Agency. An Anthropological Theory. Oxford: Clarendon.

Gero, J. (1992). Feasts and Females: Gender Ideology and Political Meals in the Andes. Norwegian Archaeological Review, 25(1), 15-30. 
Gero, J. (1999). La iconografía Recuay y el estudio de género. Gaceta Arqueológica Andina, 25, 23-44.

Giddens, A. (1979). Central Problems in Social Theory: Action, Structure, and Contradiction in Social Analysis. Berkeley: University of California Press.

Giersz, M. y Makowski, K. (Eds.) (2013). Nuevas perspectivas en la organización política wari. Andes. Boletín del Centro de Estudios Precolombinos de la Universidad de Varsovia, 9.

González-Ruibal, A. (2019). An Archaeology of the Contemporary Era. Londres: Routledge.

González-Ruibal, A. (2007). Arqueología simétrica: un giro teórico sin revolución paradigmática. Complutum, 18, 283-285.

Haas, J. y Creamer, W. (2012). Why Do People Build Monuments? Late Archaic Platform Mounds in the Norte Chico. En Burger, R. y Rosenswig, R. (Eds.). Early New World Monumentality (pp. 289-312). Gainesville: University Press of Florida.

Haas, J. y Creamer, W. (2006). Crucible of Andean Civilization: The Peruvian Coast from 3000 to 1800 BC. Current Anthropology, 47(5), 745-774.

Hagstrum, M. (1989). Technological Continuity and Change: Ceramic Ethnoarchaeology in the Peruvian Andes (tesis doctoral). Los Ángeles: University of California Los Angeles.

Harris, O. y Cipolla, C. (2017). Archaeological Theory in the New Millennium. Introducing Current Perspectives. Londres: Routledge.

Hegmon, M. (2003). Setting Theoretical Egos Aside: Issues and Theory in North American Archaeology. American Antiquity, 68(2), 213-243.

Heidegger, M. (1973). Being and Time. Oxford: Blackwell.

Herrera, A. (2008). El futuro del pasado: arqueología andina para el siglo XXI. En Jaramillo, L. G. (Ed.). Arqueología en Latinoamérica: historias, formación académica y perspectivas temáticas (pp. 167-186). Bogotá: Universidad de los Andes.

Herrera, A. (2003). La serpiente de oro y los inkas: la ocupación inka en el Alto Marañón y el puerto balsero de Pogtán. Boletín de Arqueología PUCP, 7, 189-215.

Herrera, A. (2018). Oír para creer: la arqueología de paisajes acústicos andinos. En Flores, L. (Ed.). Lugares, monumentos, ancestros: arqueologías de paisajes andinos y lejanos (pp. 237-244). Lima: Avqi.

Hodder, I. (2012). Entangled: An Archaeology of the Relationships Between Humans and Things. Malden: Wiley-Blackwell.

Hodder, I. (1992). Theory and Practice in Archaeology. Londres: Routledge.

Hodder, I. (1986). Reading the Past. Current Approaches to Interpretation in Archaeology. Cambridge: Cambridge University Press. 
Hodder, I. (Ed.) (1991). Archaeological Theory in Europe: The Last Three Decades. Londres: Routledge.

Isbell, B. (1978). To Defend Ourselves, Ecology and Ritual in an Andean Village. Long Grove: Waveland.

Isbell, W. (2018). Conclusion: SAIS and the Study of Southern Andean Prehistory. En Isbell, W., Uribe, M., Tiballi, A. y Zegarra, E. (Eds.). Images in Action. The Southern Andean Iconographic Series (pp. 785-801). Los Ángeles: Cotsen Institute of Archaeology, UCLA.

Isbell, W., Uribe, M., Tiballi, A. y Zegarra, E. (Eds.) (2018). Images in Action. The Southern Andean Iconographic Series. Los Ángeles: Cotsen Institute of Archaeology, UCLA.

Isbell, W. y Vranich, A. (2004). Experiencing the Cities of Wari and Tiwanaku. En Silverman, H. (Ed.). Andean Archaeology (pp. 167-182). Malden: Blackwell.

Jennings, Justin (Ed.) (2011). Beyond Wari Walls: Regional Perspectives on Middle Horizon Peru. Albuquerque: University of New Mexico Press.

Johnson, M. (1999). Archaeological Theory: An Introduction. Malden: Wiley-Blackwell.

Jones, A. (2001). Archaeological Theory and Scientific Practice. Cambridge: Cambridge University Press.

Kauffmann, F. y Ligabue, G. (2003). Los chachapoya(s). Moradores ancestrales de los Andes amazónicos peruanos. Lima: Universidad Alas Peruanas.

Kaulicke, P., Kondo, R., Kusuda, T. y Zapata, J. (2003). Agua, ancestros y arqueología del paisaje. Boletín de Arqueología PUCP, 7, 27-56.

Kaulicke, P. y Isbell, W. (Eds.) (2001). Huari y Tiwanaku: modelos vs. evidencias. Segunda Parte. Boletín de Arqueología PUCP, 5.

Kaulicke, P. y Isbell, W. (Eds.) (2000). Huari y Tiwanaku: modelos vs. evidencias. Primera parte. Boletín de Arqueología PUCP, 4.

Kaulicke, P. y Onuki, Y. (Eds.) (2009). El periodo Formativo: enfoques y evidencias recientes. Cincuenta años de la misión arqueológica japonesa y su vigencia. Boletín de Arqueología PUCP, 13.

Kaulicke, P. y Onuki, Y. (Eds.) (2008). El período Formativo: enfoques y evidencias recientes. Cincuenta años de la misión arqueológica japonesa y su vigencia. Boletín de Arqueología PUCP, 12.

Kaulicke, P., Urton, G. y Farrington, I. (Eds.) (2004). Identidad y transformación en el Tawantinsuyu y en los Andes coloniales. perspectivas arqueológicas y etnohistóricas. Tercera parte. Boletín de Arqueología PUCP, 8. 
Kaulicke, P., Urton, G. y Farrington, I. (Eds.) (2003). Identidad y transformación en el Tawantinsuyu y en los Andes coloniales. Perspectivas arqueológicas y etnohistóricas. Segunda parte. Boletín de Arqueología PUCP, 7.

Kaulicke, P., Urton, G. y Farrington, I. (Eds.) (2002). Identidad y transformación en el Tawantinsuyu y en los Andes coloniales. Perspectivas arqueológicas y etnohistóricas. Primera parte. Boletín de Arqueología PUCP, 6.

Klarich, E. (2005). ¿Quiénes eran los invitados? Cambios temporales y funcionales de los espacios públicos de Pukará como reflejo del cambio de las estrategias de liderazgo durante el periodo Formativo Tardío. Boletín de Arqueología PUCP, 9, 185-206.

Klaus, H. y Toyne, M. (Eds.) (2016). Ritual Violence in the Ancient Andes. Reconstructing Sacrifice on the North Coast of Peru. Austin: University of Texas Press.

Klein, N. (2007). La doctrina del shock. El auge del capitalismo del desastre. Ciudad de México: Paidós.

Knudson, K., Price, D., Buikstra, J. y Blom, D. (2004). The Use of Strontium Isotope Analysis to Investigate Tiwanaku Migration and Mortuary Ritual in Bolivia and Peru. Archaeometry, 46, 5-18.

Knudson, K., Williams, S., Osborn, R., Forgey, K. y Ryan Williams, P. (2009). The Geographic Origins of Nasca Trophy Heads Using Strontium, Oxygen, and Carbon Isotope Data. Journal of Anthropological Archaeology, 28, 244-257.

Kohn, E. (2015). Anthropology of Ontologies. Annual Review of Anthropology, 44, 311-327.

Korpisaari, A. y Chacama, J. (Eds.) (2015). El Horizonte Medio: nuevos aportes para el sur de Perú, norte de Chile y Bolivia. Lima: IFEA, Universidad de Tarapacá.

Kuznar, L. (1995). Awatimarka: The Ethnoarchaeology of an Andean Herding Community. Forth Worth: Harcourt Brace College Publishers.

Kuznar, L. (1990). Pastoralismo temprano en la sierra alta del departamento de Moquegua, Perú. Chungara, 24/25, 53-68.

Lane, K. y Herrera, A. (2005). Archaeology, Landscapes and Dreams: Science, Sacred Offerings, and the Practice of Archaeology. Archaeological Review from Cambridge, 20(1), 111-129.

Latour, B. (1993). We Have Never been Modern. Cambridge: Harvard University Press.

Lau, G. (2012). Ancient Alterity in the Andes: A Recognition of Others. Nueva York, Londres.

Lavallée, D. y Julien, M. (2012). Prehistoria de la costa extremo-sur del Perú. Los pescadores arcaicos de la Quebrada de los Burros (10000-7000 a. P.). Lima: IFEA, Fondo Editorial de la Pontificia Universidad Católica del Perú. 
Leacock, E. (1981). Myths of Male Dominance: Collected Articles on Women CrossCulturally. Nueva York: Monthly Review Press.

León, E. (2007). Orígenes humanos en los Andes del Perú. Lima: Universidad San Martín de Porres.

Lewis, C., Buikstra, J. y Stone, A. (2007). Ancient DNA and Genetic Continuity in the South Central Andes. Latin American Antiquity, 18(2), 145-160.

López-Hurtado, E. (2014). South America. En Bahn, P. (Ed.). The History of Archaeology: An Introduction (pp. 210- 227). Londres: Routledge.

Lozada, M. C. y Tantaleán, H. (Eds.) (2019). Andean Ontologies. New Archaeological Perspectives. Gainesville: University Press of Florida.

Lull, V. y Micó, R. (2001-2002). Teoría arqueológica III. Las arqueologías posprocesuales. Revista d'Arqueologia de Ponent, 11-12, 21-41.

Lull, V. y Micó, R. (1998). Teoría arqueológica II. La arqueología procesual. Revista d'Arqueologia de Ponent, 8, 61-78.

Lull, V. y Micó, R. (1997). Teoría arqueológica I. Los enfoques tradicionales: las arqueologías evolucionistas e histórico culturales. Revista d'Arqueologia de Ponent, 7, 107-128.

Lumbreras, L. G. (2007). El Imperio wari. Lima: Altazor.

Lumbreras, L. G. (1989). Chavín de Huántar en el nacimiento de la civilización andina. Lima: Instituto de Estudios Peruanos.

Lumbreras, L. G. (1974). La arqueología como ciencia social. Lima: Histar.

Malpass, M. (2016). Ancient People of the Andes. Ithaca: Cornell University Press.

Matsumoto, Y. (2010). The Prehistoric Ceremonial Center of Campanayuq Rumi: Interregional Interactions in the South-central Highlands of Peru (tesis doctoral). New Haven: Yale University.

Merleau-Ponty, M. (1962). Phenomenology of Perception. Londres: Routledge and Kegan Paul.

Millaire, J.-F. y Morlion, M. (Eds.) (2009). Gallinazo. Gallinazo: An Early Cultural Tradition on the Peruvian North Coast. Los Ángeles: Cotsen Institute of Archaeology, UCLA.

Miller, D. (1987). Material Culture and Mass Consumption. Oxford: Basil Blackwell.

Miller, D. y Tilley, C. (1996). Editorial. Journal of Material Culture, 1(1), 5-14.

Miller, D. (Ed.) (2005). Materiality. Durham: Duke University Press.

Moore, H. (1988). Feminism and Anthropology. Minneapolis: University of Minnesota Press.

Moore, J. (2014). A Prehistory of South America. Ancient Cultural Diversity on the Least Known Continent. Boulder: University Press of Colorado. 
Moro Abadía, O. (2007). Arqueología prehistórica e historia de la ciencia: hacía una historia crítica de la arqueología. Barcelona: Bellaterra.

Muro, L., Castillo, L. J. y Tomasto, E. (2019). Moche Corporeal Ontologies. Transfiguration, Ancestrality, and Death. A Perspective from the Late Moche Cemetery of San José de Moro, Northern Peru. En Lozada, M. C. y Tantaleán H. (Eds.). Andean Ontologies. New Archaeological Perspectives (pp. 116-149). Gainesville: University Press of Florida.

Murphy, M. y Boza, M. F. (2016). Convirtiendo a los vivos, disputando a los muertos: evangelización, identidad y los ancestros. Boletín de Arqueología PUCP, 21, 57-68.

Nair, S. (2015). At Home With the Sapa Inca. Architecture, Space, and Legacy at Chinchero. Austin: University of Texas Press.

Nash, D. (2009). Household Archaeology in the Andes. Journal of Archaeological Research, 17(3), 205-261.

Nesbitt, J. (2012). Excavations at Caballo Muerto: An Investigation Into the Origins of the Cupisnique Culture (disertación PhD). New Haven: Yale University.

Olsen, B. (2007). Keeping Things at Arm's Length: A Genealogy of Asymmetry. World Archaeology, 39(4), 579-588.

Onuki, Y. y Inokuchi, K. (2011). Gemelos prístinos: el tesoro del Templo de Kuntur Wasi. Lima: Congreso del Perú, Minera Yanacocha.

Ortiz, V. (2017). La investigación del periodo Precerámico Temprano en el Perú. Su historia y perspectivas. En Vega-Centeno, R. (Ed.). Repensar el Antiguo Perú. Aportes desde la arqueología (pp. 17-46). Lima: Fondo Editorial de la Pontificia Universidad Católica del Perú. Instituto de Estudios Peruanos.

Owen, B. y Goldstein, P. (2001). Tiwanaku en Moquegua: interacciones regionales y colapso. Boletín de Arqueología PUCP, 5, 169-188.

Politis, G. (2002). Acerca de la etnoarqueología en América del Sur. Horizontes Antropológicos, 18, 61-91.

Politis, G. (2004). Tendencias de la etnoarqueología en América Latina. En Politis, G. y Peretti, R. (Eds.). Teoría arqueológica en América del Sur, 85-118. Olavarría: INCUAPA.

Quilter, J. (2014). The Ancient Central Andes. Londres: Routledge.

Quilter, J. y Koons, M. (2012). The Fall of the Moche: A Critique of Claims for South America's First State. Latin American Antiquity, 23(2), 127-143.

Quilter, J. y Castillo, L. J. (Eds.) (2010). New Perspectives on Moche Political Organization. Washington D.C.: Dumbarton Oaks. 
Quilter, J., Zender, M., Spalding, K., Franco Jordán, R., Gálvez Mora, C. y Castañeda Murga, J. (2010). Traces of a Lost Language and Number System Discovered on the North Coast of Peru. American Anthropologist, 112(3), 357-369.

Ramón, G. (2013). Los alfareros golondrinos. Productores itinerantes en los Andes. Lima: IFEA, Sequilao.

Rappaport, R. (1999). Ritual and Religion in the Making of Humanity. Cambridge: Cambridge University Press.

Reindel, M. y Wagner, G. (Ed.) (2009). New Technologies for Archaeology. Multidisciplinary Investigations in Palpa and Nasca, Peru. Berlín: Springer.

Renfrew, C. y Bahn, P. (2000). Archaeology: Theories, Methods and Practice. Londres: Thames and Hudson.

Rice, P. (2014). Space-Time Perspectives on Early Colonial Moquegua. Boulder: University Press of Colorado.

Rice, P. (2012). Vintage Moquegua: History, Wine, and Archaeology on a Colonial Peruvian Periphery. Austin: University of Texas Press.

Rice, P. y Smith, G. (1989). The Spanish Colonial Wineries of Moquegua, Peru. Historical Archaeology, 23, 41-49.

Rick, J. (2015). Religión y autoridad en Chavín de Huántar. En Fux, P. (Ed.): Chavín (pp. 176-184). Lima: MALI.

Rick, J. (2013). El rol del procesualismo en la arqueología peruana en la segunda mitad del siglo XX. En Tantaleán, H. y Astuhuamán. C. (Eds.). Historia de la arqueología en el Perú de siglo $X X$ (pp. 253-288). Lima: IFEA, IAR.

Rick, J. (2008). Context, Construction, and Ritual in the Development of Authority at Chavín de Huántar. En Conklin, W. y Quilter, J. (Eds.). Chavín: Art, Architecture and Culture (pp. 3-34). Los Ángeles: Cotsen Institute of Archaeology, UCLA.

Ruiz Estrada, A. (2010). Amazonas: arqueología e historia. Lima: Universidad Alas Peruanas.

Said, E. (1978). Orientalism. Nueva York: Pantheon Books.

Sakai, M., Olano, J., Matsumoto, Y. y Takahashi, H. (2014). Centros de líneas y cerámica en las pampas de Nasca, Perú, 2010. Yamagata: Yamagata University Press.

Salcedo, L. (2019). Central Andes: Prehispanic Hunter-Gatherers. En Smith, C. (Ed.). Encyclopedia of Global Archaeology (pp. 1-33). Nueva York: Springer.

Santana, L. (2019). Entre techos de cristal y nichos académicos: estado actual de las mujeres en la arqueología peruana. Desde el Sur, 11(2), 261-281.

Schaedel, R. y Shimada, I. (1982). Peruvian Archaeology, 1946-80: An Analytic Overview. World Archaeology, 13(3), 359-371.

Schjellerup, I. (2009). Incas y españoles en la conquista de los Chachapoya. Lima: IFEA. 
Shady, R. (2006a). America's First City? The Case of Late Archaic Caral. En Isbell, W. y Silverman, H. (Eds.). Andean Archaeology III (pp. 28-66). Boston: Springer.

Shady, R. (2006b). La civilización Caral: sistema social y manejo del territorio y sus recursos. Su trascendencia en el proceso cultural andino. Boletín de Arqueología PUCP, 10, 59-89.

Shady, R., Machacuay, M., Novoa, P. y Quispe, E. (2015). Caral. 20 años recuperando la historia de la civilización Caral para el Perú y el mundo, con responsabilidad social. Lima: Zona Arqueológica Caral, Ministerio de Cultura. Shanks, M. (2007). Symmetrical Archaeology. World Archaeology, 39(4), 589-596.Shanks, M. y Tilley, C. (1987a). Reconstructing Archaeology. Theory and Practice. Londres: Routledge.

Shanks, M. y Tilley, C. (1987b). Social Theory and Archaeology. Cambridge: Polity Press.

Shimada, I. y Vega-Centeno, R. (2011). Peruvian Archaeology: Its Growth, Characteristics, Practice, and Challenge. En Lozny, L. (Ed.). Comparative Archaeologies (pp. 569612). Nueva York: Springer.

Shimada, I., Shinoda, K.-I., Farnum, J., Corruccini, R. y Watanabe, H. (2004). An Integrated Analysis of PreHispanic Mortuary Practices. A Middle Sicán Case Study. Current Anthropology, 45(3), 369-402.

Shimada, I. y Fitzsimmons, J. (Eds.). (2015). Living with the Dead in the Andes. Arizona: University of Arizona Press.

Sillar, B. (2000). Shaping Culture: Making Pots and Constructing Households: An Ethnoarchaeological Study of Pottery Production, Trade and Use in the Andes. Oxford: British Archaeological Reports.

Sillar, B. (2009). The Social Agency of Things? Animism and Materiality in the Andes. Cambridge Archaeological Journal, 19(3), 367-377.

Sillar, B. y Ramón, G. (2016). Using the Present to Interpret the Past: The Role of Ethnographic Studies in Andean Archaeology. World Archaeology, 48(5), 656-673.

Silverblatt, I. (1987). Moon, Sun, and Witches. Gender Ideologies and Class in Inca and Colonial Peru. Princeton: Princeton University Press.

Silverman, H. y Isbell, W. (Eds.) (2008). Handbook of South American Archaeology. Nueva York: Springer.

Spence-Morrow, G. y Swenson, E. (2019). Moche Mereology. Synecdochal Ontologies at the Late Moche Site of Huaca Colorada, Peru. En Lozada, M. C. y Tantaleán, H. (Eds.). Andean Ontologies. New Archaeological Perspectives. (pp. 150-182). Gainesville: University Press of Florida.

Spivak, G. (1999). A Critique of Postcolonial Reason: Toward a History of the Vanishing Present. Cambridge: Harvard University Press. 
Stanish, C (2003). Ancient Titicaca. The Evolution of Complex Society in Southern Peru and Northern Bolivia. Berkeley: University of California Press.

Stanish, C. (1989). Household Archeology: Testing Models of Zonal Complementarity in the South Central Andes. American Anthropologist, 91(1), 7-24.

Swenson, E. (2012). Moche Ceremonial Architecture as Thirdspace: The Politics of Place-Making in the Ancient Andes. Journal of Social Archaeology, 12(1), 3-28.

Tantaleán, H. (2016). Una historia de la arqueología peruana. Lima: Instituto de Estudios Peruanos, Universidad San Francisco de Quito.

Tantaleán, H. y Astuhuamán, C. (Eds.) (2013). Historia de la arqueología en el Perú del siglo $X X$. Lima: IFEA, IAR.

Tantaleán, H. y Stanish, C. (Eds.) (2017). Cerro del gentil. Un sitio Paracas en el valle de Chincha, costa sur del Perú. Lima: PACH Press.

Tavera, C. (2019). Una mirada feminista a la comunidad arqueológica peruana. Desde el Sur, 11(2), 239-260.

Tello, J. C. (1943). Discovery of the Chavin Culture in Peru. American Antiquity, 9(1), 135-160.

Tilley, C. (1994). A Phenomenology of Landscape: Places, Paths, and Monuments. Oxford: Berg.

Toohey, J. (2011). Formal and Stylistic Variation in the Ceramic Assemblage at the Late Intermediate Period Site of Yanaorco in the Cajamarca Highlands of Northern Peru. Nawpa Pacha, 31(2), 171-200.

Topic, J. y Topic, T. (2000). Hacia la comprensión del fenómeno Huari: una perspectiva norteña. Boletín de Arqueología PUCP, 4, 181-217.

Traslaviña, A., Chase, Z., Van Valkenburgh, P. y Weaver, B. (Eds.) (2016a). Arqueología histórica en el Perú (primera parte). Boletín de Arqueología PUCP, 20.

Traslaviña, A., Chase, Z., Van Valkenburgh, P. y Weaver, B. (Eds.) (2016b). Arqueología histórica en el Perú (segunda parte). Boletín de Arqueología PUCP, 21.

Trigger, B. (2006). A History of Archaeological Thought. Cambridge: Cambridge University Press.

Trigger, B. (1989). A History of Archaeological Thought. Cambridge: Cambridge University Press.

Tung, T. (2012). Violence, Ritual, and the Wari Empire: A Social Bioarchaeology of Imperialism in the Ancient Andes. Gainesville: University Press of Florida.

Turner, V. (1969) The Ritual Process. Ithaca: Cornell University Press.

Uceda, S. (2018). El complejo arqueológico Huacas del Sol y de la Luna. Una visión 25 años después. En Ibérico, P. (Ed.). Perú: arqueología de los Andes (pp. 15-96). Trujillo: Instituto de los Andes. 
Uceda, S. (2010). Los Contextos Urbanos de Producción Artesanal en el Complejo Arqueológico de las Huacas del Sol y de la Luna. Bulletin de l'Institut Français d'Études Andines 39(2):243-297.

Uceda, S. y Rengifo, C. (2006). La especialización del trabajo: teoría y arqueología. el caso de los orfebres mochicas. Bulletin de l'Institut Français d'Études Andines, 35(2), 149-185.

Ucko, Peter (ed.) 1995 Theory in Archaeology: A World Perspective. Routledge, Londres. Urban, P. y Schortman, E. (2019). Archaeological Theory in Practice. Londres: Routledge. VanValkenburgh, P. (2016). Produciendo Chérrepe: reducción, etnia y performance en los valles de Zaña y Chamán, siglos XVI y XVII. Boletín de Arqueología PUCP, 20 , 129-148.

Vega-Centeno, R. (2017). El periodo Arcaico Tardío en perspectiva regional. Nuevos aportes. En Vega-Centeno, R. (Ed.). Repensar el Antiguo Perú. Aportes desde la arqueología (pp. 85-119). Lima: Fondo Editorial de la Pontificia Universidad Católica del Perú. Instituto de Estudios Peruanos.

Vega-Centeno, R. (Ed.) (2017). Repensar el Antiguo Perú. Aportes desde la arqueología. Lima: Fondo Editorial de la Pontificia Universidad Católica del Perú. Instituto de Estudios Peruanos.

Vega-Centeno, R. (2010). Cerro Lampay: Architectural Design and Human Interaction in the North Central Coast of Peru. Latin American Antiquity, 21(2), 115-145.

Verano, J. (2016). Holes in the Head. The Art and Archaeology of Trepanation in Ancient Peru. Washington: Dumbarton Oaks.

Verdesio, G. (2014). El subalternismo en el marco de la teoría arqueológica: hacia un posible diálogo entre matrices teóricas. En Rivolta, M. C., Montenegro, M., Menezes, L. y Nastri, J. (Eds.). Multivocalidad y activaciones patrimoniales en arqueología: perspectivas desde Sudamérica (pp. 67-87). Buenos Aires: Universidad de Buenos Aires, Fundación de Historia Antural Félix Azara.

Viveiros de Castro, E. (2010). Metafísicas caníbales. Lineas de antropología postestructural. Buenos Aires: Katz.

Weismantel, M. (2013). Inhuman Eyes: Looking at Chavín de Huantar. En Watts, C. (Ed.). Relational Archaeologies. Human, Animal, Things (pp. 21-41). Nueva York: Routledge.

Weismantel, M. (2015). Seeing Like an Archaeologist: Viveiros de Castro at Chavín de Huantar. Journal of Social Archaeology, 15(2), 139-159.

Wernke, S. (2016). La producción de poder en el entorno construido a través de la invasión española, valle del Colca (Perú). Boletín de Arqueología PUCP, 20, 149-166. 
Wernke, S. (2013). Negotiated Settlements: Andean Communities and Landscapes under Inka and Spanish Colonialism. Gainesville: University Press of Florida.

Wernke, S., Oré, G. Hernández, C. Norman, S., Kohut, L., Waller, L. y Vylegzhanina, V. (2017). Ejes de articulación: análisis de la red espacial del Qhapaq Ñan en el sur del Perú. En Chacaltana, S., Arkush, E. y Marcone, G. (Eds.). Nuevas tendencias en el estudio de los caminos (pp. 124-143). Lima: Ministerio de Cultura.

Willey, G. y Sabloff, J. (1980). A History of American Archaeology. San Francisco: W. H. Freeman and Company.

Witmore, C. (2007). Symmetrical Archaeology: Excerpts of a Manifesto. World Archaeology, 39(4), 546-562.

Wołoszyn, J., González, L. y Rozwadowski, A. (2019). The Petroglyphs of Toro Muerto: New Documentation and Discoveries at the Largest South American Rock Art Complex. Antiquity, 93(372), e37, 1-8.

Yataco, J. J. (2013). Revisión de las evidencias de Pikimachay, Ayacucho, ocupación del Pleistoceno final en los Andes centrales. Boletín de Arqueología PUCP, 15, 247-274.

Yépez, E. y Jennings, J. (Eds.). (2012). ¿Wari en Arequipa? Análisis de los contextos funerarios de La Real. Arequipa: Museo Arqueológico José María Morante, Universidad Nacional de San Agustín.

Yoffee, N. y Sherratt, A. (Eds.). (1989). Archaeological Theory: Who Sets the Agenda? Cambridge: Cambridge University Press.

Young, M. (2017). De la montaña al mar: intercambio entre la sierra centro-sur y la costa sur durante el Horizonte Temprano. Boletín de Arqueología PUCP, 22, 9-34.

Ziółkowski, M., Jennings, J. Belán, L. A. y Drusini, A. (Eds.) (2009). Arqueología del área centro sur andina. Andes 7. Boletín del Centro de Estudios Precolombinos de la Universidad de Varsovia. 